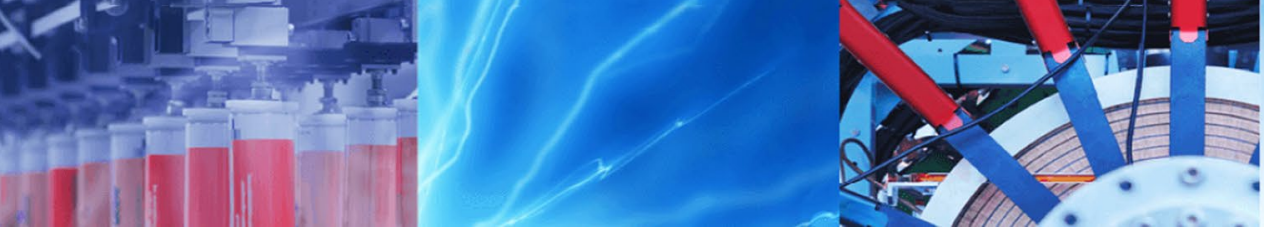

Research Article

\title{
Quadratic growth hypothesis for reaction time prediction and 'rate of growth' based classification of cumulus
}

\author{
P. Kumar ${ }^{1} \cdot$ Deba Prasad Pati ${ }^{2}$ \\ () Springer Nature Switzerland AG 2019
}

\begin{abstract}
Research is motivated by unsatisfactory results in hail mitigation operations, anywhere in the world. In this paper, a new concept of quadratic growth hypothesis (QGH) has been proposed and examined in the prediction of hailstorm. Another new concept of reaction time (RT) has been presented which is useful for efficient seeding in hail mitigation campaigns. Given complex nature of cumulus growth, rate of growth of cumulus cloud $(r)$ has been broadly categorized as slow $(r \leq 0.2 \mathrm{dBZ} / \mathrm{min})$, moderate $(0.2<r<0.8 \mathrm{dBZ} / \mathrm{min})$ and fast $(r \geq 0.8 \mathrm{dBZ} / \mathrm{min})$. Often cumulus shows reverse growth too. It is found that QGH-based predictions are $100 \%$ correct for slow-growing cumulus and $62.5 \%$ accurate for moderate. However, QGH predictions are incorrect when the cumulus growth reverses or when it is fast. Empirically a 'QGH-Rectangle' has been identified wherein QGH is precisely valid. Prediction skill scores [= (correct prediction/total predictions made)] of $0.79,0.79$ and 0.75 are obtained from scan intervals (time interval between the beginnings of any two adjacent volume scans) of 10-, 12- and 19-min radar data, respectively. Amongst the three data sets, 10-min scan interval is operationally safer for RT computation during hail mitigation campaigns. In most of the cases, RT may range from 17.3 to $29.6 \mathrm{~min}$. Maximum RT of $43 \mathrm{~min}$ is also noted for slow-growing cumulus. Linear extrapolation (LE) has been used to predict the cumulus cloud motion speed which has been observed from $5 \mathrm{~m} / \mathrm{s}$ to as high as $19.3 \mathrm{~m} / \mathrm{s}$. It is noted that larger scan interval of Doppler weather radar data would exhibit more consistent and reliable speed prediction by LE method.
\end{abstract}

Keywords Quadratic growth hypothesis · Reaction time · Pre Hail Detection Algorithm · QGH-Rectangle · Cumulus classification on rate of growth

\section{Introduction}

\subsection{Hail control strategy}

Several billions of dollars is lost, each year, due to hail damage to life and property, throughout the world (Kumar [13]). The first scientific attempt towards hail mitigation was made by Sulakvelidze [26]. He hypothesized that by artificially seeding of cumuliform clouds with cloud condensation nuclei (CCN) for warm region of cloud and/or with ice nuclei (IN) for cold region of cloud, the condensed droplets or ice crystals increase within the cloud. For each gram of seeding substance in the pyrotechnic cartridge, the resulting smoke may generate $\mathrm{IN}$ in the range of $10^{10}-10^{16}$ nuclei. The count depends on atmospheric temperature, pressure and humidity. This estimate is based on the chamber particle counters from De Mott [4]. On average, it could be $10^{14}$ per gram [20]. Nucleation and precipitation attain the optimal rate values, between $-19^{\circ} \mathrm{C}$ and $-3.8^{\circ} \mathrm{C}[15]$. After nucleation, they all compete to collect the available water vapour and grow larger altogether. As a result, cloud water is distributed into several small ice crystals or small hails, above $0^{\circ} \mathrm{C}$ isotherm, within the cloud. These ice crystals or small hails would either become much

P. Kumar, prabhat.kumar@mitcoe.edu.in; Deba Prasad Pati, pati_debaprasad@rediffmail.com | ${ }^{1}$ Department of Mathematics, MIT-World Peace University, Pune, India. ${ }^{2}$ National Initiative on Climate Resilient Agriculture Project, Pune, India.

SN Applied Sciences (2019) 1:439| https://doi.org/10.1007/s42452-019-0421-8

Received: 26 November 2018 / Accepted: 27 March 2019 / Published online: 9 April 2019 
smaller or completely melt into water during their travel below zero degree isotherm and turn into rain or drizzle. This hypothesis of hail control, however, does not specify the control of any specific size of hail. It is a general strategy so that the sizes of newly born hailstones are small enough at the place of their origin itself.

Hypothesis was first applied in Georgia (part of erstwhile Soviet Union) which subsequently laid strong scientific foundation for the control of hailstorm world over. Between mid-1970s and beginning of 1980s, two large experiments were undertaken to evaluate the effectiveness of cloud seeding in Western Europe (Switzerland, France and Germany) known as The Great Experiment [7] and another in the USA known as National Hail Research Experiment [12]. The results from both the experiments showed that statistically there was no significant difference in the occurrence of hail between seeded- and not seeded hail-bearing clouds. Albeit uncertainty on the effectiveness of hail control by cloud seeding prevailed and World Meteorological Organisation in 2007 decided not to recommend Hail Suppression any more, still several European countries continued with their Hail Suppression programmes.

Unsatisfactory results did not mean that seeding approach for hail mitigation was incorrect; rather, it indicated that disdain of correct time and level of seeding lead to unsatisfactory results. Concept of efficient seeding agents was also not well known during those experiments. Kumar [15] has defined percentage cartridge efficiency of seeding agent (e.g. pyrotechnic cartridge). Effective seeding [5] in the shortest possible time is known as efficient seeding. The most efficient seeding could be obtained if the agents are released in optimum temperature/pressure range vis-a-vis levels within the cloud. As regards the correct time of seeding, it is well known that seeding done prior to the hail formation is the most appropriate time of seeding. If hails have already formed in the cloud, then they have to fall on ground. The causes of unsatisfactory success in the hail control under several projects, worldwide, have been discussed by Kumar [13]. Besides quantity of seeding, there are three preliminary steps required in any efficient hail mitigation operation.

(1) Identify a growing cumulus cloud in its early stage and forecast 'if it would turn into a hailstorm or not'. Early stage is defined as $\leq 20 \mathrm{dBZ}$, onwards of cloud reflectivity value (Kumar and Pati [14].

(2) What is the total reaction time (i.e. time duration for any cumulus to grow from 20 to $45 \mathrm{dBZ}$ ) for the seeding operation? It is assumed that hailstones are already available in the cumulus cloud when the cloud reflectivity crosses $45 \mathrm{dBZ}$ thresholds [22, $23,28,29]$. Hence, for hail suppression operation, seeding must be done prior to hail formation in the cloud-i.e. during reaction time.

(3) What are the location and speed of motion of cloud?

Therefore, as a primary step, for a successful hail mitigation operation, as far as possible one must track a growing cumulus right from the very early stage [step-(1)] to quickly predict the reaction time [step-(2)]. Last 50 years of history of software developments related to thunderstorm was having primary objective of predicting thunderstorm's occurrence, e.g. 'time and place'. None were aimed for forecasting the reaction time; albeit, they did successfully compute the cloud motion [step-(3)], very well. For completeness before mentioning the Pre Hail Detection Algorithm (PHDA) based on quadratic growth hypothesis, a brief history of all the previous softwares related to thunderstorms is summarized hereunder.

Cross-correlation analysis of the reflectivity field was one of the first storms tracking technique [11]. Advance Traffic Management System Cross-Correlation Algorithm [10] was developed to provide automatic storm tracking for Federal Aviation Administration (FAA). Yet another technique developed in storm tracking was by matching storms at one point to their counterparts at later time. This is known as centroid tracking. Wilk and Gray [27] had applied a centroid identification technique to Weather Surveillance Radar (WSR-57) signal in order to estimate storm motion and precipitation. This technique and variations thereof were also applied by Zittle [30] and Brady et al. [3]. Boak et al. [2] developed a centroid identification algorithm, and Forsyth [8] developed centroid tracking technique. Centroid technique also provides a tool for scientific analysis of a storm as three-dimensional entities.

Dixon and Wiener [6] presented real-time automated identification tracking and short-term forecasting of thunderstorm based on volume scan weather radar data. They defined storm as contiguous region exceeding thresholds of reflectivity and size. Primary threshold of cumulus, by them, was fixed as 30-40 dBZ. They referred reflectivity of 25-30 dBZ as mesoscale convective complexes, which may or may not grow into thunderstorm. The software was named as 'Thunderstorm Identification Tracking, Analysis and Nowcasting' (TITAN). This could track the echo for forecasting of hail [1]. However, threshold of $30 \mathrm{dBZ}$ was too high for computing the reaction time. Higher threshold would give less reaction time and subsequently limit the efficient seeding duration. In Oct 1996, Hail Detection Algorithm (HDA) by Witt et al. [29] could provide hail indications in growing cumulus cloud. The centroid tracking algorithm of RAINBOW software defined cells based on user-defined single threshold level. The multiple threshold criterions for storm detection are implemented in the WDSS-II software-Warning Decision Support System 
Integrated Information. In the WDSS-II, the Storm Cell Identification and Tracking (SCIT) algorithm uses centroid identification and tracking technique to identify and track individual storms and provide cell characteristic information $[21,24]$. No cloud motion velocity data are processed by this algorithm. This 3D depiction of storm is the input for Hail Detection Algorithm (HAD). Multi-Radar Severe Storm Analysis Program (MR-SSAP)—Stumpf et al. [25]— combines the two-dimensional information from multiple radars and mosaics it into virtual volume scans [19], with the latest elevation scan of data replacing the one from a previous volume scan. Lakshamann et al. [16-18] developed an algorythm that distinguishes precipitating and non-precipitating radar echo.

HDA [29] was limited to showing one of the four possible indications for each storm, identified, e.g. positive, probable, none or insufficient data. Enhanced HDA was developed only for hail detection which gave more information, e.g. probability of Hail, probability of severe size of hail (Diameter more than $1.9 \mathrm{~cm}$.), maximum expected hail size and Sever Hail Index (SHI). Again the threshold initial detection value was similar to TITAN; hence, it was unsuitable for reaction time computation.

Vaisala Company patented Interactive Radar Information System (IRIS) which is capable of generating products including six composite of all Doppler Weather Radar images. They include information like reflectivity, range, azimuth, coordinates and time. Kumar and Pati [14] have presented the method of extracting the pixel information from the PPI display of radar imagery with the help of IRIS software and MATLAB [9]. For hail mitigation programs, one not only needs spontaneous prediction of hail but also maximum possible reaction time for seeding. This needed spotting the growing cumulus at much early stage than primary threshold of any of the existing software. Hence a simple quadratic algorithm has been presented in the present paper as basis of Pre Hail Detection Algorithm (PHDA) which not only identifies the prospects of a growing cumulus to develop into a hailstorm in its early stage but also predicts the reaction time.

\subsection{Important terminologies}

\subsubsection{Radar reflectivity}

Radar base reflectivity product is a display of echo intensity (reflectivity) measured in $\mathrm{dBZ}$ (decibels). $d B Z$ is the logarithmic scale for measuring radar reflectivity factor. Kumar and Pati [14] have explained that how reflectivity of pixel is extracted by identifying Region of Interest (ROI) of cluster and then that of Point of Interest (POI). For example, under RGB scheme $[R G B=(R$ (red), $G$ (Green) and $B$ (Blue)] in the Radar Screen (Scope), the convective cloud echo is known as region of interest that we could crop for further analysis.

As shown in Fig. 1, it is a rectangular box with nearly 80 small boxes or squares with a different reflectivity which is the ROI. Here each box is known as pixel of an image, i.e. the smallest unit of a digital image which gives information about the dimension ( $x$-coordinate and $y$-coordinate) and the colour content of the image. In ROI, the entire suspicious cloud can be analysed by finding the average reflectivity of a particular region. The growth of the entire region may be studied. Marginal regions of colour gradient from blue to green are Point of Interest (POI) which is subset of ROI. In POI, one can select any pixel of interest (out of 80 small boxes). If mouse pointer is put over any point/pixel, we can get that point's coordinates and the colour component of that Point-which actually gives the reflectivity.

$\mathrm{ROI}$ is required when we have a larger area of interest for hail growth analysis. POI can be used if colour gradient is clearly discernible just by visualizing the screen, so that the reaction time (RT) could be calculated faster, just by analysing that particular cloud point. This paper explains the principles which have been attempted by authors, manually, in their last paper [14]. However, same can be automated in future radar software developments, using Digital Image Processing (DIP).

\subsubsection{Reaction time}

Any exercise to control hailstone within the cloud must be attempted prior to its embryonic stage. Lower threshold of radar reflectivity of 'hailstone containing cloud' has been well accepted as $45 \mathrm{dBZ}[22,23,28,29]$ albeit it may be argued to be observed at $\geq 52 \mathrm{dBZ}$, too. Also in areas where there are heavy convective rains, $45 \mathrm{dBZ}$ can also be achieved with no hail present. If the hails form at reflectivity higher than $45 \mathrm{dBZ}$, then more reaction time would be

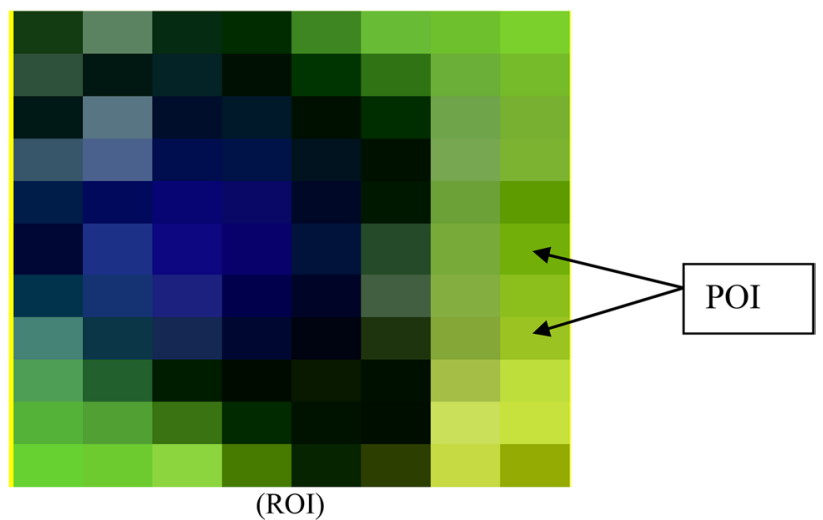

Fig. 1 Region of Interest (ROI) and Point of Interest (POI) 
available. Nevertheless, hails or no hails, operational safety would be relatively better if 'pre-planned hail mitigation operation' is for shorter period obtained by assuming lower threshold at $45 \mathrm{dBZ}$.

Moreover for cloud at greater distances, even larger hydrometeors may exhibit reflectivity less than $45 \mathrm{dBZ}$ because their effect is averaged out over the entire resolution volume, which could be of the order of cubic kilometres. Hence, very long distance observational range may also affect this value. Therefore, S-Band radar with operational range limit of $\approx 200 \mathrm{~km}$ is recommended for using the bench mark of $45 \mathrm{dBZ}$.

Advance prediction of time period when a growing cumulus would attain $45 \mathrm{dBZ}$ of reflectivity is, therefore, important for hail mitigation campaigns. Now the following points are pertinent:

(1) Total reaction time (TRT) may be defined as the time taken by any cumulus cloud with reflectivity $20 \mathrm{dBZ}$ to grow till its reflectivity reaches $45 \mathrm{dBZ}$ [14].

(2) Available reaction time (ART) is the time actually available within the TRT for action against the growing cumulus cloud.

Seeding within reaction time, therefore, will restrict large growth of any hydrometeor in the cloud. Consequently, while falling below $0{ }^{\circ} \mathrm{C}$ isotherm levels, they will either partially melt down to very small size or completely melt down into rain droplets.

\subsection{Velocity of the cloud}

Different types of seeding techniques have been described by Kumar [13]. From operational safety considerations, most commonly used are direct injection by firing rockets from ground from static location and top-down delivery system by dropping pyrotechnic cartridges from aircraft. While the former needs large area of air space to be cordoned off to avoid any collateral damage to any other passenger aircraft flying in the path of rockets projectile, the latter technique often suffers with the problem of inaccurate drop location or inappropriate level. The significance of seeding at appropriate levels for 'efficient seeding' has been discussed by Kumar [15]. Hence, direct injection by launching rocket vertically upwards from the ground with in the available reaction time is safer, more efficient option. For this strategy, rockets are needed to be transported by the helicopter below the cloud base. This technique, however, needs precise prediction of cloud [11] motion speed, too. Though there are several softwares to predict the speed of the cloud, it has been noted in the present paper that a simple technique, based on the three point cloud locations, can also be used to predict the speed, precisely.

In the present paper, therefore, with the sole objective of improving results in hail mitigation campaigns, new concepts of Quadratic Growth Hypothesis (QGH) and reaction time have been proposed and examined, for three different scan intervals of radar data. QGH is important to obtain the reaction time vis-à-vis available reaction time for effective and efficient seeding of any growing cumulus cloud. As the rate of cumulus growth widely varies, Sect. 2 describes as how they may be scientifically classified. Section 3 presents the details of radar data from widely separated weather radar station in India. Section 4 describes the Quadratic Growth Hypothesis (QGH) and algorithms for computing reaction time and cloud motion speed. Application of QGH-based Pre Hail Detection Algorithm (PHDA) and its efficacy in predicting hail for slow-, medium- and fast-growing cumulus clouds, for different 'scan interval data', are examined in Sect. 5 . This section is aimed to present the feasibility of QGH concept in operational hail mitigation campaigns. Section 6 further clarifies the application of PHDA for hailstorm prediction from radar data derived from two scan intervals. The limitation of PHDA for predicting hail is discussed in Sect. 7, and discussion of strength and weakness of QGH is presented in Sect. 8 before concluding and summarizing the findings in Sect. 9.

\section{Classification of cumulus}

Increased or decreased pattern of radar reflectivity is a complicated phenomenon which depends on dynamics and thermal conditions in the environmental background. Radar reflectivity of the cumulus clouds, therefore, could be termed as proxy of its growth or decay features. Before proposing the mathematical formulation of cumulus growth, it is essential to categorize the rate of observed growth of growing cumulus cloud under different environmental conditions. Observed rate of growth $(r)$ of cumulus cloud can be defined as the ratio of difference of reflectivity at two times $(\Delta R)$ with corresponding time interval $(\Delta T)$. Data obtained in the present study are based on scanned interval of 10,12 and $19 \mathrm{~min}$. Hence, classifications are based on shorter scan time $(\Delta T)$ of $10 \mathrm{~min}$ only. Scientific categorization of any scatter distribution must be around its mean value $(\mu)$. If $\sigma$ is the standard distribution, then the central class of the scatter could be a range from $(\mu-\sigma)$ to $(\mu+\sigma)$. Lower class can be classified as $\leq(\mu-\sigma)$ and upper class as $\geq(\mu+\sigma)$. Hence, threeclass categorization has been adopted in this study, e.g. slow, medium and fast. The average rate of growth $(r)$ of cumulus is observed to be $0.49 \mathrm{dBZ} / \min (\approx 0.5 \mathrm{dBZ})$ with 
standard deviation $(\sigma)=0.3$. It ranges from 0.1 to $1.6 \mathrm{dBZ} /$ min. Therefore, based on the rate of growth, radar clusters can be divided into three categories: slow-growing cumulus when $r \leq 0.2 \mathrm{dBZ} / \mathrm{min}$, moderate-growing cumulus when $0.2<r<0.8 \mathrm{dBZ} / \mathrm{min}$ and fast-growing cumulus when $r \geq 0.8 \mathrm{dBZ} / \mathrm{min}$. Quite often the reflectivity of the growing cumulus has been observed to reduce temporarily, before again picking up the positive growth. This rate of reversal in reflectivity $\left(r_{n}\right)$, where suffix $n$ denotes the 'negative rate' is computed from Tables 4,5 and 6 . The average $r_{n}=0.3 \mathrm{dBz} / \mathrm{min}$ with standard deviation $(\sigma)=0.1$. Therefore, in conformity with the definition given for $r$, the $r_{n}$ may also be termed as slow when $r_{n} \leq 0.2 \mathrm{dBZ} / \mathrm{min}$, moderate when $0.2<r_{n}<0.4 \mathrm{dBZ} / \mathrm{min}$ and fast when $r_{n} \geq 0.4 \mathrm{dBZ} / \mathrm{min}$. These definitions would be used in the subsequent discussions in this paper.

\section{Radar data}

To obtain sample data from entire India, three radar stations were identified one each from north India, e.g. Patna, Central India, e.g. Nagpur, and south India, e.g. Mumbai. For first two stations, data were obtained from India Meteorological Department (IMD) routine observational radars at Patna $\left(25^{\circ} 36^{\prime} \mathrm{N}, 85^{\circ} 9^{\prime} 31 \mathrm{E}\right)$ and Nagpur $\left(21.14^{\circ} \mathrm{N}\right.$, $79.08^{\circ} \mathrm{E}$ ) for 10 -min interval, for hailstorm days. Time interval between the beginnings of any two adjacent volume scans is known as scan interval. Radar reflectivity, radial velocity and spectral width were collected at 10-min interval for ten elevations from $0.2^{\circ}$ to $21^{\circ}$ on 16 March 2013 and 1 May 2012. DWR was M/S Beijing Metstarmake single polarization mode, S-Band $(\approx 2800 \mathrm{MHz}$ ) with PRF of 200-1200 Hz (selectable). It was operated at 2 RPM with volume scan repeated in $10 \mathrm{~min}$. Archived DWR (IMD) data for Mumbai $\left(19.07^{\circ} \mathrm{N}, 72.87^{\circ} \mathrm{E}\right)$ were selectively picked from three different years' data when hailstorms were reported in the vicinity. Data of 21 April 2015 were at 10-min interval. In 2014 on 6, 11, 12, 18 March data were at 12-min interval and in 2013 on 2, 3, 6 and 8 June data time interval was even larger at $19 \mathrm{~min}$. This DWR at Mumbai was BEL Mk-II make S-band (2700-2900 MHz). As the time intervals in different data were not same, simple quadratic extrapolation algorithm developed in the present work was separately applied to same time interval data and then compared. The entire radar product, collected for the present study from India Meteorological Department, was without any spurious echoes, due to built-in software in the radar.

The generated binary data file from Doppler Weather Radar's (DWR's) Plan Position Indictor (PPI) data was interactively accessed through the inbuilt software feature of Interactive Radar Information System (IRIS) to arrive at the

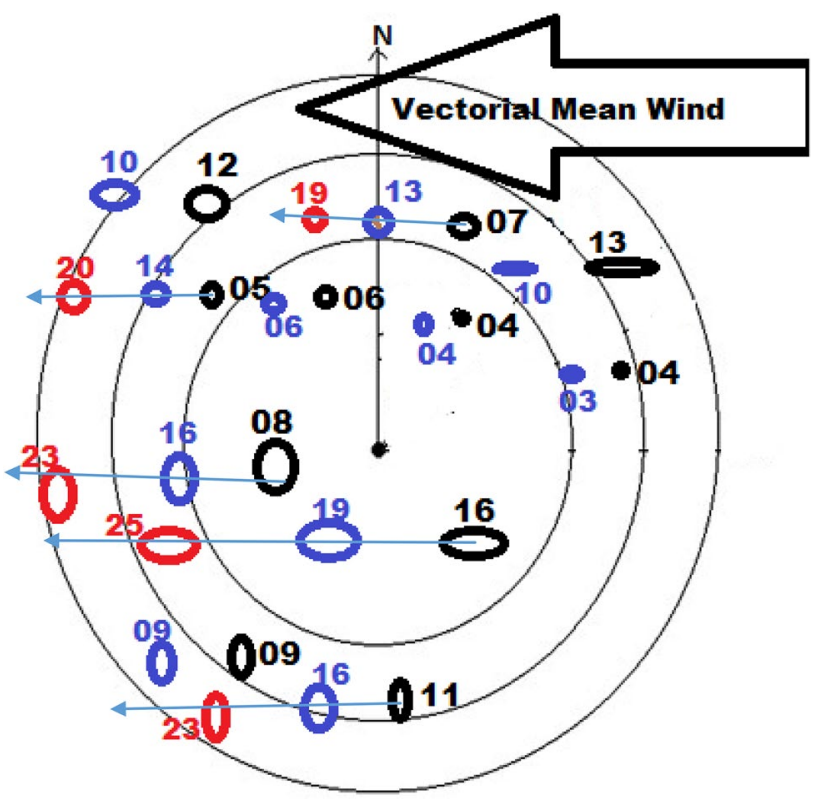

Fig. 2 PPI display after initially ignoring echoes with reflectivity more than $20 \mathrm{dBZ}$ with easterly mean wind. Black spots or shapes represent echo location during first scan. Blue spots or shapes are the locations of the same echoes during the second scan, and red colour echoes represent their locations during the third scan. The numbers close to echoes represent their reflectivity. It is average reflectivity of Point of Interest (POI) (Kumar and Pati [14]). Growing clusters, e.g. [07, 13, 19], [05, 14, 20], [08, 16, 23], [16, 19, 25] and [11, $16,23]$, are indicated by arrows through them

final data values rather than simple extrapolation from imageries.

\section{Quadratic Growth Hypothesis (QGH) algorithm}

Quadratic Growth Hypothesis (QGH) proposed in this paper is based on the assumption that slow- to moderate-growing cumulus reflectivity follows quadratic relation with time. Quadratic term refers to quadratic equation which can simulate the temporal growth profile of a growing cumulus. Constant coefficients of the quadratic equation would be different for every cumulus growth. Nevertheless, this can be spontaneously generated by taking three temporal observations of reflectivity of the cumulus. Once the temporal growth profile's mathematical graphic is known, prediction is possible. In Sect. 4.1, it is explained in detail. To prove the validity of assumption, if we assume that the hypothesis is incorrect, then predictions made based on the assumptions should also be incorrect, but on the contrary we would see that predictions for hailstorm in slow growth category are $100 \%$ correct, and in moderate growth category, it is 
$62.3 \%$ correct (Fig. 13). Fast-growing cumulus cannot be formulated under QGH hypothesis; hence, different mathematical formulations have to be explored for this category of cumulus.

Nevertheless, authors' claim certainly needs further validation with larger data set in India and from other parts of the tropics and even extra tropics, too, for examining its universal validity, under slow and moderate growth category in particular and all the categories in general. This would also clarify if the hypothesis is regional phenomena or global in nature.

\subsection{Hail prediction and reaction time based on QGH}

It is generally expected that the reaction time is transient short span in a growing cumulus and hence might range from a few minutes to an hour or so, depending on the rate of growth of convection. Further, any two radar observations can be taken only after certain time interval ' $t$ '; where $t$ is the scan time; hence, if two observations are needed, then first one can be at the start time $\left(T_{0}\right)$ and then second one after $t$ time, i.e. at $T_{0}+t$. Therefore, larger number of observations, for making prediction based on extrapolation scheme, would consume larger time and hence render shorter available reaction time (ART). On the other hand, if only two observations are taken at $T_{0}$ and $T_{0}+t$, then only straight line fit is possible. Straight line fit is not appropriate, since two consecutive observations exhibiting same reflectivity

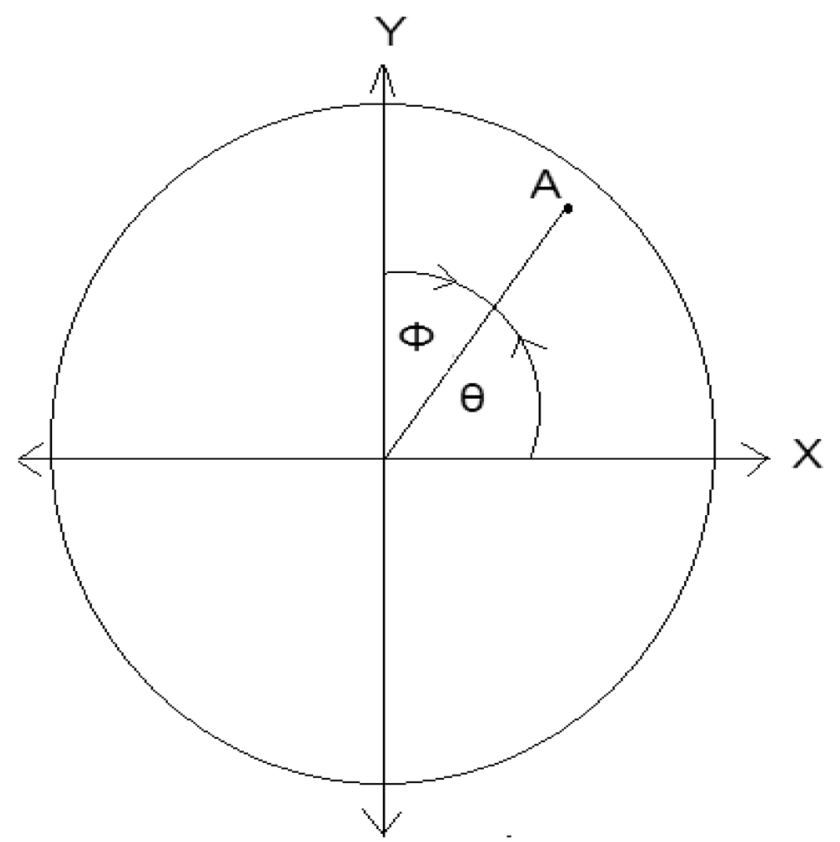

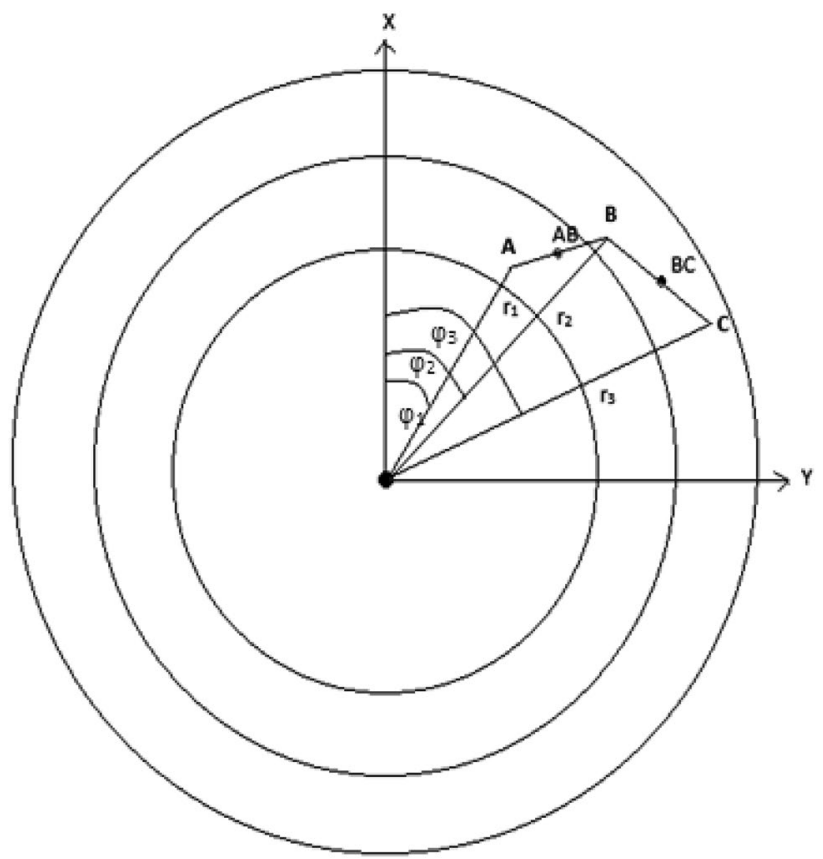

Fig. 4 Cloud cluster locations A, B, C on PPI display at different times

or decrease in reflectivity would always predict no hail. Skill score computed based on this scheme is poor at 0.42 . Hence, better trade-off between the reasonably good ART and least prediction time with high skill score is three observations at $T_{0}, T_{0}+t$ and at $T_{0}+2 t$. A simple Quadratic Growth Hypothesis (QGH) has, therefore, been adopted in the present paper. This hypothesis presumes that 'Slow or Moderately Growing Cumulus' reflectivity $(Z)$ in (dBZ) could be related with time $(T)$ in minutes as

$Z=a T^{2}+b T+c$,

where $a, b$ and $c$ are arbitrary constants.

Let $T_{i}$ be the time of $i$ th observation $(i=1,2,3,4)$ and $T_{4}(i=4)$ is the predicted time when $45 \mathrm{dBZ}$ reflectivity would be achieved by the convective cloud.

If $\left(T_{i+1}-T_{i}\right)$ is the time interval between the two successive observations (in minutes), then $\left(T_{4}-T_{3}\right)$ is the reaction time.

The radar reflectivity at time $T_{1}, T_{2}$ and $T_{3}$ in minutes is $Z_{1}, Z_{2}$ and $Z_{3}$ in $\mathrm{dBZ}$, respectively.

With Quadratic Growth Hypothesis (QGH), the three may be presented as:

$$
\begin{aligned}
& Z_{1}=a T_{1}^{2}+b T_{1}+c \\
& Z_{2}=a T_{2}^{2}+b T_{2}+c \\
& Z_{3}=a T_{3}^{2}+b T_{3}+c
\end{aligned}
$$

Fig. 3 Relation between $\theta$ and $\varphi$ in the first quadrant 
Table 1 Skill score $D^{5}{ }_{10}$

\begin{tabular}{llrr}
\hline Actual & \multicolumn{2}{l}{ Expected } \\
\cline { 2 - 4 } & Yes & No & Total \\
\hline Yes & 5 & 3 & 8 \\
No & 1 & 10 & 11 \\
Total & 6 & 13 & 19
\end{tabular}

Skill score $15 / 19=0.79$

Minimum/maximum reaction time in current data sample: $16 / 43$ min

Mean/standard deviation: 24/8.95 $\min$

Table 2 Skill score $D_{12}^{12}$

\begin{tabular}{lrrr}
\hline Actual & \multicolumn{3}{l}{ Expected } \\
\cline { 2 - 4 } & \multicolumn{1}{c}{ Yes } & No & Total \\
\hline Yes & 12 & 4 & 16 \\
No & 2 & 11 & 13 \\
Total & 14 & 15 & 29 \\
\hline
\end{tabular}

Skill score $23 / 29=0.79$

Minimum/maximum reaction time in current data sample: $14 / 39$ min

Mean/standard deviation: 23.8/6.15 $\min$

Table 3 Skill score $D^{8}{ }_{19}$

\begin{tabular}{lllr}
\hline Actual & \multicolumn{3}{l}{ Expected } \\
\cline { 2 - 4 } & Yes & No & Total \\
\hline Yes & 8 & 3 & 11 \\
No & 0 & 1 & 1 \\
Total & 8 & 4 & 12 \\
\hline
\end{tabular}

Skill score $=9 / 12=0.75$

Minimum/maximum reaction time in current data sample: $18 / 39$ min

Mean/standard deviation: 26.3/13.0 $\mathrm{min}$

where $a, b, c$ are arbitrary constants whose values can be obtained by solving Eqs. (1), (2) and (3). Having obtained the values of constants $a, b$ and $c$, the reaction time $\left(T_{4}-T_{3}\right)$ may be obtained by solving Eq. (4).

$45=a T^{2}+b T+c$

Only real roots are to be taken for hail formation. Complex or imaginary roots indicate no hail. Also in case of two real roots, only lower of the two real roots is used for computing the available reaction time (ART). This is to meet the operational safety. Higher real root would give more reaction time which might compromise with the operational safety. Practically, the challenge remains as how to identify the $T_{1}, T_{2}$ and $T_{3}$ values.

Here it is to be mentioned that seeding for hail mitigation should be done only for those clouds which may develop into hailstorms in future. Hence, only growing cumulus clouds (may be one or more than one at a time) are of interest to hail control missions, so that seeding them within the available reaction time would prevent the embryonic hail stones to grow larger. Radar operator, therefore, has to manually identify only those cloud echoes on the PPI-scope which are in the range of less than $20 \mathrm{dBZ}$ of reflectivity. Figure 2 shows an example of manual selection of echoes. Suppose mean wind is easterly, and all echoes are being steered by that. Let black spots represent echo locations during first scan. Blue spots are the locations of the same echoes during the second scan, and red echoes represent their locations during the third scan. The numbers close to echoes represent their reflectivity values in dBZ. Radar operator has to manually discard all those echoes whose reflectivity during the second scan is less than or equal to those during the first scan. It may be assumed that these echoes are not growing - although some echoes may again grow after temporary reversal. QGH may not make correct prediction for reverse growth cases. Such exceptions are the limitation of the QGH. It is explained in Sect. 7 by example. During the third scan, one is left with a few echoes whose reflectivity is greater than that of first. In Fig. 2, from north to south, the clusters are shown by cutting arrows which indicate growth, e.g. [07, 13, 19], $[05,14,20],[08,16,23],[16,19,25]$ and $[11,16,23]$. Radar operator has to include only these clusters in the computation of reaction time. If first scan is at $4 \mathrm{~h} 13 \mathrm{~min}$ UTC, then $T_{1}=13$. Thereafter, for $10-\mathrm{min}$ scan interval $T_{2}=23$ and $T_{3}=33 \mathrm{~min}$.

Nevertheless, radar operator has to be physically alert by closely identifying the shape and texture of the echoes during each scan and chase the specific echo, keeping in mind their movements due to steering winds. New born echoes during the scans are to be astutely differentiated by their textures and shapes and are to be ignored while chasing any particular echo.

\subsection{Speed calculation}

Significance of speed of the cloud is discussed in Sect. 1.3. If cloud seeding has to done by vertical firing of rockets after landing of helicopter below the cloud, then its spontaneous speed would help the pilot to timely chase the suspicious cloud before landing below it. 
Table 4 Reaction time estimation $D_{0}^{5}$

\begin{tabular}{|c|c|c|c|c|c|c|c|c|c|}
\hline $\begin{array}{l}\text { Radar/date } \\
\text { (region) }\end{array}$ & Time (UTC) & $\begin{array}{l}\text { Range/azi- } \\
\text { muth }\end{array}$ & Cluster no. & $\begin{array}{l}\text { Reflectivity } \\
\text { (dBZ) } Z_{1} \\
Z_{2}, Z_{3}\end{array}$ & $\begin{array}{l}\text { Time } \\
\left(\text { UTC) } T_{1},\right. \\
T_{2}, T_{3}\end{array}$ & $\begin{array}{l}\text { Reac- } \\
\text { tion time } \\
\text { computed } \\
\text { as per PHDA } \\
\left(T_{4}-T_{3}\right)\end{array}$ & $\begin{array}{l}\text { Expected } \\
\text { hailstorm } \\
\text { occur- } \\
\text { rence time } \\
\left(T_{3}+\text { col. } 7\right)\end{array}$ & $\begin{array}{l}\text { Actual } \\
\text { occurrence } \\
\text { (when } \\
\text { reflectivity } \\
\text { actually } \\
\text { reached } \\
45 \mathrm{dBZ} \text { in } \\
\text { radar obser- } \\
\text { vation) }\end{array}$ & $\begin{array}{l}\text { Difference } \\
\text { (actual- } \\
\text { expected) in } \\
\text { minute }\end{array}$ \\
\hline 1 & 2 & 3 & 4 & 5 & 6 & 7 & 8 & 9 & 10 \\
\hline \multirow{3}{*}{$\begin{array}{l}\text { NAG- } \\
\text { PUR/16-3-13 } \\
\text { (Akola) }\end{array}$} & \multirow[t]{3}{*}{$4: 10$} & \multirow[t]{3}{*}{$245 \mathrm{~km} / 290^{\circ}$} & \multirow[t]{3}{*}{ Cluster-1 } & 21 & $4: 10$ & \multirow[t]{3}{*}{$27 \mathrm{~min}$} & \multirow[t]{3}{*}{$4: 57$} & \multirow[t]{3}{*}{$5: 10$} & \multirow[t]{3}{*}{13} \\
\hline & & & & 23 & $4: 20$ & & & & \\
\hline & & & & 27 & $4: 30$ & & & & \\
\hline \multirow{3}{*}{$\begin{array}{l}\text { NAG- } \\
\text { PUR/16-3-13 } \\
\text { (Brahmapuri) }\end{array}$} & \multirow[t]{3}{*}{$3: 30$} & \multirow[t]{3}{*}{$75 \mathrm{~km} / 135^{\circ}$} & \multirow[t]{3}{*}{ Cluster-2 } & 26 & $3: 30$ & \multirow[t]{3}{*}{ Null } & \multirow{3}{*}{$\begin{array}{c}\text { No hail- } \\
\text { storm }\end{array}$} & \multirow{3}{*}{$\begin{array}{c}\text { No hail- } \\
\text { storm }\end{array}$} & \multirow[t]{3}{*}{0} \\
\hline & & & & 28 & $3: 40$ & & & & \\
\hline & & & & 30 & $3: 50$ & & & & \\
\hline \multirow{3}{*}{$\begin{array}{l}\text { NAG- } \\
\text { PUR/16-3-13 } \\
\text { (Gondia) }\end{array}$} & \multirow[t]{3}{*}{$4: 10$} & \multirow[t]{3}{*}{$160 \mathrm{~km} / 85^{\circ}$} & \multirow[t]{3}{*}{ Cluster-3 } & 22 & $4: 10$ & \multirow[t]{3}{*}{ Null } & \multirow{3}{*}{$\begin{array}{c}\text { No hail- } \\
\text { storm }\end{array}$} & \multirow{3}{*}{$\begin{array}{c}\text { No hail- } \\
\text { storm }\end{array}$} & 0 \\
\hline & & & & 26 & $4: 20$ & & & & \\
\hline & & & & 29 & $4: 30$ & & & & \\
\hline NAG- & $3: 30$ & 100 km/ & Cluster-4 & 28 & $3: 30$ & Null & No hail- & No hail- & 0 \\
\hline PUR/16-3-13 & & $\mathrm{Az}-225^{\circ}$ & & 33 & $3: 40$ & & storm & storm & \\
\hline & & & & 32 & $3: 50$ & & & & \\
\hline NAG- & $4: 10$ & $240 \mathrm{~km} / 270^{\circ}$ & Cluster-5 & 28 & $4: 10$ & Null & No hail- & No hail- & 0 \\
\hline PUR/16-3-13 & & & & 33 & $4: 20$ & & storm & storm & \\
\hline & & & & 30 & $4: 30$ & & & & \\
\hline & $3: 50$ & $240 \mathrm{~km} / 274^{\circ}$ & Cluster-6 & 22 & $3: 50$ & Null & No hail- & No hail- & 0 \\
\hline PUR/16-3-13 & & & & 28 & 4:00 & & storm & storm & \\
\hline & & & & 32 & $4: 10$ & & & & \\
\hline NAG- & $6: 10$ & $220 \mathrm{~km} / 315^{\circ}$ & Cluster-7 & 26 & $6: 10$ & Abnormal & Hailstorm & Hailstorm & - \\
\hline PUR/16-3-13 & & & & 28 & $6: 20$ & growth & & & \\
\hline & & & & 44 & $6: 30$ & & & & \\
\hline & & & & 40 & $6: 40$ & & & & \\
\hline NAG- & 3.30 & $220 \mathrm{~km} / 315^{\circ}$ & Cluster-8 & 26 & 3.30 & Null & No hail- & No hail- & 0 \\
\hline PUR/16-3-13 & & & & 37 & 3.40 & & storm & storm & \\
\hline & & & & 36 & 3.50 & & & & \\
\hline NAG- & $3: 30$ & $145 \mathrm{~km} / 350^{\circ}$ & Cluster-9 & 26 & $3: 30$ & Null & No hail- & No hail- & 0 \\
\hline PUR/16-3-13 & & & & 30 & $3: 40$ & & storm & storm & \\
\hline & & & & 32 & $3: 50$ & & & & \\
\hline PATNA/1-5-12 & $9: 22$ & $230 \mathrm{~km} /$ & Cluster-10 & 33 & $9: 22$ & Null & No hail- & No hail- & 0 \\
\hline (Tribhuban & & $345^{\circ}$ & & 36 & $9: 32$ & & storm & storm & \\
\hline & & & & 38 & $9: 52$ & & & & \\
\hline PATNA/1-5-12 & $10: 12$ & $230 \mathrm{~km} / 345^{\circ}$ & Cluster-11 & 26 & $10: 12$ & $43 \mathrm{~min}$ & $11: 15$ & $11: 20$ & 5 \\
\hline (Simara) & & & & 29 & $10: 22$ & & & & \\
\hline & & & & 32 & $10: 32$ & & & & \\
\hline PATNA/21-4- & $10: 02$ & $240 \mathrm{~km} / 28^{\circ}$ & Cluster-12 & 23 & $10: 02$ & Null & No hail- & No hail- & 0 \\
\hline 15) (Tanak- & & & & 28 & $10: 12$ & & storm & storm & \\
\hline & & & & 30 & $10: 22$ & & & & \\
\hline PATNA/21-4-15 & $10: 42$ & $210 \mathrm{~km} / 35^{\circ}$ & Cluster-13 & 24 & $10: 42$ & Null & No hail- & $12: 12$ & 0 \\
\hline (Tanakpur) & & & & 34 & $10: 52$ & & storm & & \\
\hline & & & & 32 & 11:02 & & & & \\
\hline
\end{tabular}


Table 4 (continued)

\begin{tabular}{|c|c|c|c|c|c|c|c|c|c|}
\hline $\begin{array}{l}\text { Radar/date } \\
\text { (region) }\end{array}$ & Time (UTC) & $\begin{array}{l}\text { Range/azi- } \\
\text { muth }\end{array}$ & Cluster no. & $\begin{array}{l}\text { Reflectivity } \\
\text { (dBZ) } Z_{1} \\
Z_{2}, Z_{3}\end{array}$ & $\begin{array}{l}\text { Time } \\
\left(\text { UTC) } T_{1},\right. \\
T_{2}, T_{3}\end{array}$ & $\begin{array}{l}\text { Reac- } \\
\text { tion time } \\
\text { computed } \\
\text { as per PHDA } \\
\left(T_{4}-T_{3}\right)\end{array}$ & $\begin{array}{l}\text { Expected } \\
\text { hailstorm } \\
\text { occur- } \\
\text { rence time } \\
\left(T_{3}+\text { col. } 7\right)\end{array}$ & $\begin{array}{l}\text { Actual } \\
\text { occurrence } \\
\text { (when } \\
\text { reflectivity } \\
\text { actually } \\
\text { reached } \\
45 \mathrm{dBZ} \text { in } \\
\text { radar obser- } \\
\text { vation) }\end{array}$ & $\begin{array}{l}\text { Difference } \\
\text { (actual- } \\
\text { expected) in } \\
\text { minute }\end{array}$ \\
\hline 1 & 2 & 3 & 4 & 5 & 6 & 7 & 8 & 9 & 10 \\
\hline \multirow{3}{*}{$\begin{array}{l}\text { PATNA/21-4-15 } \\
\text { (Simara) }\end{array}$} & \multirow[t]{3}{*}{$14: 22$} & \multirow[t]{3}{*}{$180 \mathrm{~km} / 10^{\circ}$} & \multirow[t]{3}{*}{ Cluster-14 } & 25 & $14: 22$ & \multirow[t]{3}{*}{$18 \mathrm{~min}$} & \multirow[t]{3}{*}{$15: 00$} & \multirow[t]{3}{*}{$14: 52$} & \multirow[t]{3}{*}{-8} \\
\hline & & & & 29 & $14: 32$ & & & & \\
\hline & & & & 33 & $14: 42$ & & & & \\
\hline \multirow{3}{*}{$\begin{array}{l}\text { PATNA/21-4-15 } \\
\text { (STM) }\end{array}$} & \multirow[t]{3}{*}{$13: 52$} & \multirow[t]{3}{*}{$125 \mathrm{~km} / 40^{\circ}$} & \multirow[t]{3}{*}{ Cluster-15 } & 26 & $13: 52$ & \multirow[t]{3}{*}{$16 \mathrm{~min}$} & \multirow[t]{3}{*}{$14: 28$} & \multirow[t]{3}{*}{$14: 32$} & \multirow[t]{3}{*}{4} \\
\hline & & & & 32 & $14: 02$ & & & & \\
\hline & & & & 36 & $14: 12$ & & & & \\
\hline \multirow{3}{*}{$\begin{array}{l}\text { PATNA/21-4-15 } \\
\text { (MGR) }\end{array}$} & \multirow[t]{3}{*}{$16: 02$} & \multirow[t]{3}{*}{$170 \mathrm{~km} / 93^{\circ}$} & \multirow[t]{3}{*}{ Cluster-16 } & 27 & $16: 02$ & \multirow[t]{3}{*}{ Null } & \multirow{3}{*}{$\begin{array}{l}\text { No hail- } \\
\text { storm }\end{array}$} & \multirow[t]{3}{*}{$16: 32$} & \multirow[t]{3}{*}{0} \\
\hline & & & & 34 & $16: 12$ & & & & \\
\hline & & & & 32 & $16: 22$ & & & & \\
\hline \multirow{3}{*}{$\begin{array}{l}\text { PATNA/21-4-15 } \\
\text { (MDP) }\end{array}$} & \multirow[t]{3}{*}{$14: 12$} & \multirow[t]{3}{*}{$240 \mathrm{~km} / 58^{\circ}$} & \multirow[t]{3}{*}{ Cluster-17 } & 26 & $14: 12$ & \multirow[t]{3}{*}{ Null } & \multirow{3}{*}{$\begin{array}{l}\text { No hail- } \\
\text { storm }\end{array}$} & \multirow[t]{3}{*}{$14: 42$} & \multirow[t]{3}{*}{0} \\
\hline & & & & 36 & $14: 22$ & & & & \\
\hline & & & & 30 & $14: 32$ & & & & \\
\hline \multirow{3}{*}{$\begin{array}{l}\text { PATNA/21-4-15 } \\
\text { (Simara) }\end{array}$} & \multirow[t]{3}{*}{$10: 42$} & $200 \mathrm{~km} / 15^{\circ}$ & Cluster-18 & 24 & $15: 02$ & $16 \mathrm{~min}$ & $15: 38$ & No hail & 0 \\
\hline & & & & 28 & $12: 12$ & & & storm & \\
\hline & & & & 34 & $12: 24$ & & & & \\
\hline PATNA/21-4-15 & $10: 42$ & $170 \mathrm{~km} / 28^{\circ}$ & Cluster-19 & 24 & $16: 02$ & Null & No hail- & No hail- & 0 \\
\hline (STM) & & & & 28 & $16: 12$ & & storm & storm & \\
\hline & & & & 30 & $12: 22$ & & & & \\
\hline
\end{tabular}

If $\varphi$ is the azimuth angle in degrees, measured clockwise from north and $\theta$ the angle made by the target with the positive $x$-axis (anticlockwise), then for first quadrant, as shown in Fig. 3, $\theta=\frac{\pi}{2}-\varphi_{r}$, and for 2 nd, 3rd and 4th quadrants $\theta=\frac{5 \pi}{2}-\varphi_{r}$; where $\varphi_{r}=\frac{\pi \varphi}{180}$ where $\varphi_{r}$ is in radians and $\varphi$ is in degrees.

Conversion of $r, \theta$ into $x$ and $y$ components is made by taking $x=r \operatorname{Cos} \theta$ and $y=r \operatorname{Sin} \theta$.

The speed is computed at the midpoint of two time observations by dividing the linear distance between the two points by the time interval. The locations of points $A\left(r_{1}, \varphi_{1}\right), B\left(r_{2}, \varphi_{2}\right), C\left(r_{3}, \varphi_{3}\right)$ are shown in Fig. 4 ; the time associated with point $A\left(r_{1}, \varphi_{1}\right)$ is $t_{1}$; and the range and azimuth are $r_{1}$ and $\varphi_{1}$, respectively.

Similarly at point $B\left(r_{2}, \varphi_{2}\right)$, associated time is $t_{2}$ and the range and azimuth are $r_{2}$ and $\left(\varphi_{2}\right)$, respectively, and at point $C\left(r_{3}, \varphi_{3}\right)$, associated time is $t_{3}$ and the range and azimuth are $r_{3}$ and $\varphi_{3}$, respectively.
Then, at time $T_{\mathrm{AB}}=\frac{t_{1}+t_{2}}{2}$, speed at $\mathrm{AB}$ is: $v_{1}=\frac{\sqrt{\left(x_{2}-x_{1}\right)^{2}+\left(y_{2}-y_{1}\right)^{2}}}{t_{2}-t_{1}}$ and speed at $B C$ at time $T_{B C} \frac{t_{2}+t_{3}}{2}$ is: $v_{2}=\frac{\sqrt{\left(x_{3}-x_{2}\right)^{2}+\left(y_{3}-y_{2}\right)^{2}}}{t_{3}-t_{2}}$.

Hence, speed at time $t_{3}$ is given by: $\left(\frac{v_{2}-v_{1}}{T_{\mathrm{BC}}-T_{\mathrm{AB}}}\right) t_{3}+C$, where $C=\left(\frac{v_{2} T_{A B}-v_{1} T_{B C}}{T_{A B}-T_{B C}}\right)$.

\section{Pre Hail Detection Algorithm (PHDA)-based hail prediction and reaction time}

As the available data from different regions of India had varying scan intervals of 10,12 and $19 \mathrm{~min}$, corresponding data sets are named as $D_{i}^{j}$ where $i$ specifies the scan interval (e.g. 10, 12 or $19 \mathrm{~min}$ ) and $j$ specifies the number of hailstorms actually occurred in the data set. For example, $D_{10}^{5}$ data set means data with 10-min scan interval included 5 actually occurred hailstorms. Separate analyses of data sets help to examine the role of scan time interval 
Table 5 Reaction time estimation $D_{12}^{2}$

\begin{tabular}{|c|c|c|c|c|c|c|c|c|c|}
\hline $\begin{array}{l}\text { Radar/date } \\
\text { (region) }\end{array}$ & Time (UTC) & $\begin{array}{l}\text { Range/azi- } \\
\text { muth }\end{array}$ & Cluster no. & $\begin{array}{l}\text { Reflectivity } \\
\text { (dBZ) } Z_{1} \\
Z_{2}, Z_{3}\end{array}$ & $\begin{array}{l}\text { Time } \\
\text { (UTC) } T_{1} \text {, } \\
T_{2}, T_{3}\end{array}$ & $\begin{array}{l}\text { Reac- } \\
\text { tion time } \\
\text { computed } \\
\text { as per PHDA } \\
\left(T_{4}-T_{3}\right)\end{array}$ & $\begin{array}{l}\text { Expected } \\
\text { hailstorm } \\
\text { occur- } \\
\text { rence time } \\
\left(T_{3}+\text { col. } 7\right)\end{array}$ & $\begin{array}{l}\text { Actual } \\
\text { occurrence } \\
\text { (when } \\
\text { reflectivity } \\
\text { actually } \\
\text { reached } \\
45 \mathrm{dBZ} \text { in } \\
\text { radar obser- } \\
\text { vation) }\end{array}$ & $\begin{array}{l}\text { Difference } \\
\text { (actual- } \\
\text { expected) in } \\
\text { minute }\end{array}$ \\
\hline 1 & 2 & 3 & 4 & 5 & 6 & 7 & 8 & 9 & 10 \\
\hline \multirow{3}{*}{$\begin{array}{l}\text { MUM- } \\
\text { BAl/6-3-14 } \\
(\mathrm{AHW})\end{array}$} & \multirow[t]{3}{*}{$8: 27$} & \multirow[t]{3}{*}{$215 \mathrm{~km} / 28^{\circ}$} & \multirow[t]{3}{*}{ Cluster 1} & 22 & $8: 27$ & \multirow[t]{3}{*}{ Null } & \multirow{3}{*}{$\begin{array}{l}\text { No hail- } \\
\text { storm }\end{array}$} & \multirow{3}{*}{$\begin{array}{c}\text { No hail- } \\
\text { storm }\end{array}$} & \multirow[t]{3}{*}{0} \\
\hline & & & & 29 & $8: 39$ & & & & \\
\hline & & & & 31 & $8: 51$ & & & & \\
\hline \multirow{3}{*}{$\begin{array}{l}\text { MUM- } \\
\text { BAI/6-3-14 } \\
\text { (Nasik) }\end{array}$} & \multirow[t]{3}{*}{ 9:39 } & \multirow[t]{3}{*}{$225 \mathrm{~km} / 40^{\circ}$} & \multirow[t]{3}{*}{ Cluster 2} & 24 & $9: 39$ & \multirow[t]{3}{*}{ Null } & \multirow{3}{*}{$\begin{array}{l}\text { No hail- } \\
\text { storm }\end{array}$} & \multirow{3}{*}{$\begin{array}{c}\text { No hail- } \\
\text { storm }\end{array}$} & \multirow[t]{3}{*}{0} \\
\hline & & & & 29 & 9:51 & & & & \\
\hline & & & & 33 & $10: 03$ & & & & \\
\hline \multirow{3}{*}{$\begin{array}{l}\text { MUM- } \\
\text { BAI/11-3-14 } \\
\text { (DMN) }\end{array}$} & \multirow[t]{3}{*}{ 11:03 } & \multirow[t]{3}{*}{$170 \mathrm{~km} / 22^{\circ}$} & \multirow[t]{3}{*}{ Cluster 3} & 24 & 11:03 & \multirow[t]{3}{*}{$22 \min$} & \multirow[t]{3}{*}{$11: 49$} & \multirow[t]{3}{*}{$11: 51$} & \multirow[t]{3}{*}{2} \\
\hline & & & & 28 & $11: 15$ & & & & \\
\hline & & & & 32 & $11: 27$ & & & & \\
\hline MUM- & $12: 03$ & $150 \mathrm{~km} / 35^{\circ}$ & Cluster 4 & 20 & $12: 03$ & $15 \mathrm{~min}$ & $12: 42$ & $12: 39$ & -3 \\
\hline BAI/11-3-14 & & & & 25 & $12: 15$ & & & & \\
\hline & & & & 32 & $12: 27$ & & & & \\
\hline MUM- & $17: 27$ & $195 \mathrm{~km} / 58^{\circ}$ & Cluster 5 & 28 & $17: 27$ & $14 \mathrm{~min}$ & $18: 05$ & $18: 03$ & -2 \\
\hline $\mathrm{BAI} / 11-3-14$ & & & & 30 & $17: 39$ & & & & \\
\hline & & & & 37 & $17: 51$ & & & & \\
\hline MUM- & $17: 39$ & $160 \mathrm{~km} / 65^{\circ}$ & Cluster 6 & 23 & $17: 39$ & $25 \mathrm{~min}$ & $18: 28$ & $18: 15$ & -13 \\
\hline $\mathrm{BAl} / 11-3-14$ & & & & 27 & $17: 51$ & & & & \\
\hline gar) & & & & 32 & $18: 03$ & & & & \\
\hline MUM- & $18: 27$ & $210 \mathrm{~km} / 50^{\circ}$ & Cluster 7 & 24 & $17: 39$ & Null & No hail- & 19:03 & 0 \\
\hline BAl/11-3-14 & & & & 32 & $17: 51$ & & storm & & \\
\hline & & & & 28 & $18: 03$ & & & & \\
\hline MUM- & $14: 12$ & $220 \mathrm{~km} / 125^{\circ}$ & Cluster 8 & 22 & $14: 12$ & $33 \mathrm{~min}$ & $15: 09$ & $15: 12$ & 3 \\
\hline BAl/11-3-14 & & & & 25 & $14: 24$ & & & & \\
\hline & & & & 29 & $14: 36$ & & & & \\
\hline MUM- & $20: 03$ & $230 \mathrm{~km} / 55^{\circ}$ & Cluster 9 & 23 & 20:03 & Null & No hail- & No hail- & 0 \\
\hline $\mathrm{BAI} / 11-3-14$ & & & & 28 & $20: 15$ & & storm & storm & \\
\hline & & & & 32 & $20: 27$ & & & & \\
\hline MUM- & $16: 36$ & $240 \mathrm{~km} / 110^{\circ}$ & Cluster 10 & 23 & $16: 36$ & Null & No hail- & No hail- & 0 \\
\hline BAI/11-3-14 & & & & 28 & $16: 48$ & & storm & storm & \\
\hline & & & & 30 & $17: 00$ & & & & \\
\hline & $4: 48$ & $205 \mathrm{~km} / 80^{\circ}$ & Cluster 11 & 36 & $4: 48$ & Null & No hail- & No hail- & 0 \\
\hline BAI/12-3-14 & & & & 38 & $5: 00$ & & storm & storm & \\
\hline $\begin{array}{l}\text { (Anemauna- } \\
\text { gar) }\end{array}$ & & & & 39 & $5: 12$ & & & & \\
\hline MUM- & $10: 24$ & $120 \mathrm{~km} / 120^{\circ}$ & Cluster 12 & 24 & $10: 24$ & $16 \mathrm{~min}$ & $11: 04$ & No hail- & 0 \\
\hline BAI/12-3-14 & & & & 28 & $10: 36$ & & & storm & \\
\hline & & & & 38 & $10: 48$ & & & & \\
\hline MUM- & $11: 12$ & $170 \mathrm{~km} / 135^{\circ}$ & Cluster 13 & 25 & $11: 12$ & Null & No hail- & No hail- & 0 \\
\hline BAl/12-3-14 & & & & 30 & $11: 24$ & & storm & storm & \\
\hline & & & & 34 & 11:36 & & & & \\
\hline
\end{tabular}


Table 5 (continued)

\begin{tabular}{|c|c|c|c|c|c|c|c|c|c|}
\hline $\begin{array}{l}\text { Radar/date } \\
\text { (region) }\end{array}$ & Time (UTC) & $\begin{array}{l}\text { Range/azi- } \\
\text { muth }\end{array}$ & Cluster no. & $\begin{array}{l}\text { Reflectivity } \\
(\mathrm{dBZ}) Z_{1} \\
Z_{2}, Z_{3}\end{array}$ & $\begin{array}{l}\text { Time } \\
\text { (UTC) } T_{1} \text {, } \\
T_{2}, \mathrm{~T}_{3}\end{array}$ & $\begin{array}{l}\text { Reac- } \\
\text { tion time } \\
\text { computed } \\
\text { as per PHDA } \\
\left(T_{4}-T_{3}\right)\end{array}$ & $\begin{array}{l}\text { Expected } \\
\text { hailstorm } \\
\text { occur- } \\
\text { rence time } \\
\left(T_{3}+\text { col. } 7\right)\end{array}$ & $\begin{array}{l}\text { Actual } \\
\text { occurrence } \\
\text { (when } \\
\text { reflectivity } \\
\text { actually } \\
\text { reached } \\
45 \mathrm{dBZ} \text { in } \\
\text { radar obser- } \\
\text { vation) }\end{array}$ & $\begin{array}{l}\text { Difference } \\
\text { (actual- } \\
\text { expected) in } \\
\text { minute }\end{array}$ \\
\hline 1 & 2 & 3 & 4 & 5 & 6 & 7 & 8 & 9 & 10 \\
\hline \multirow{3}{*}{$\begin{array}{l}\text { MUM- } \\
\text { BAI/12-3-14 } \\
\text { (Pune) }\end{array}$} & \multirow[t]{3}{*}{$11: 12$} & \multirow[t]{3}{*}{$125 \mathrm{~km} / 100^{\circ}$} & \multirow[t]{3}{*}{ Cluster 14} & 25 & $11: 12$ & \multirow[t]{3}{*}{$28 \mathrm{~min}$} & \multirow[t]{3}{*}{$12: 04$} & \multirow[t]{3}{*}{$12: 00$} & \multirow[t]{3}{*}{-4} \\
\hline & & & & 28 & $11: 24$ & & & & \\
\hline & & & & 33 & 11:36 & & & & \\
\hline \multirow{3}{*}{$\begin{array}{l}\text { MUM- } \\
\text { BAI/12-3-14) } \\
\text { (Satara) }\end{array}$} & \multirow[t]{3}{*}{$12: 00$} & \multirow[t]{3}{*}{$180 \mathrm{~km} / 140^{\circ}$} & \multirow[t]{3}{*}{ Cluster 15} & 23 & $12: 00$ & \multirow[t]{3}{*}{$24 \mathrm{~min}$} & \multirow[t]{3}{*}{$12: 48$} & \multirow[t]{3}{*}{$12: 36$} & \multirow[t]{3}{*}{-12} \\
\hline & & & & 28 & $12: 12$ & & & & \\
\hline & & & & 32 & $12: 24$ & & & & \\
\hline \multirow{3}{*}{$\begin{array}{l}\text { MUM- } \\
\text { BAI/12-3-14) } \\
\text { (Pune) }\end{array}$} & \multirow[t]{3}{*}{$11: 24$} & \multirow[t]{3}{*}{$140 \mathrm{~km} / 95^{\circ}$} & \multirow[t]{3}{*}{ Cluster 16} & 25 & $11: 24$ & \multirow[t]{3}{*}{$32 \min$} & \multirow[t]{3}{*}{$12: 20$} & \multirow[t]{3}{*}{$12: 24$} & \multirow[t]{3}{*}{4} \\
\hline & & & & 28 & $11: 36$ & & & & \\
\hline & & & & 32 & $11: 48$ & & & & \\
\hline MUM- & $12: 00$ & $200 \mathrm{~km} / 80^{\circ}$ & Cluster 17 & 26 & $12: 00$ & $14 \min$ & $12: 38$ & $12: 36$ & -2 \\
\hline $\mathrm{BAl} / 12-3-14$ & & & & 28 & $12: 12$ & & & & \\
\hline $\begin{array}{l}\text { (Anemadna- } \\
\text { gar) }\end{array}$ & & & & 34 & $12: 24$ & & & & \\
\hline MUM- & $12: 00$ & $240 \mathrm{~km} / 150^{\circ}$ & Cluster 18 & 22 & $12: 00$ & $17 \mathrm{~min}$ & $12: 41$ & No hail- & 0 \\
\hline BAl/12-3-14 & & & & 28 & $12: 12$ & & & storm & \\
\hline & & & & 34 & $12: 24$ & & & & \\
\hline MUM- & $14: 24$ & $200 \mathrm{~km} / 130^{\circ}$ & Cluster 19 & 27 & $14: 24$ & Null & No hail- & $15: 12$ & 0 \\
\hline BAI/12-3-14 & & & & 32 & $14: 36$ & & storm & & \\
\hline & & & & 29 & $14: 48$ & & & & \\
\hline MUM- & $14: 12$ & $180 \mathrm{~km} / 100^{\circ}$ & Cluster 20 & 24 & $14: 12$ & $39 \mathrm{~min}$ & 15:05 & 15:12 & 7 \\
\hline BAI/12-3-14 & & & & 28 & $14: 24$ & & & & \\
\hline & & & & 32 & $14: 26$ & & & & \\
\hline MUM- & $16: 00$ & $220 \mathrm{~km} / 70^{\circ}$ & Cluster 21 & 24 & $16: 00$ & Null & No hail- & $16: 48$ & 0 \\
\hline BAI/12-3-14 & & & & 32 & $16: 12$ & & storm & & \\
\hline & & & & 28 & $16: 24$ & & & & \\
\hline MUM- & $16: 00$ & $190 \mathrm{~km} / 120^{\circ}$ & Cluster 22 & 25 & $16: 00$ & $30 \mathrm{~min}$ & $16: 54$ & $17: 00$ & 6 \\
\hline $\mathrm{BAl} / 12-3-14$ & & & & 26 & $16: 12$ & & & & \\
\hline (Jatard) & & & & 30 & $16: 24$ & & & & \\
\hline MUM- & $16: 36$ & $140 \mathrm{~km} / 110^{\circ}$ & Cluster 23 & 26 & $16: 36$ & Null & No hail- & No hail- & 0 \\
\hline $\mathrm{BAI} / 12-3-14$ & & & & 32 & $16: 48$ & & storm & storm & \\
\hline & & & & 34 & $17: 00$ & & & & \\
\hline & $17: 48$ & $200 \mathrm{~km} / 110^{\circ}$ & Cluster 24 & 25 & $17: 48$ & Null & No hail- & $18: 36$ & 0 \\
\hline $\mathrm{BAl} / 12-3-14$ & & & & 32 & $18: 00$ & & storm & & \\
\hline gar) & & & & 28 & $18: 12$ & & & & \\
\hline MUMBAI/ & $11: 26$ & $220 \mathrm{~km} / 160^{\circ}$ & Cluster 25 & 23 & $11: 26$ & Null & No hail- & No hail- & 0 \\
\hline 18-3-14 & & & & 32 & $11: 38$ & & storm & storm & \\
\hline & & & & 34 & $11: 50$ & & & & \\
\hline MUMBAI/ & $13: 38$ & $150 \mathrm{~km} / 130^{\circ}$ & Cluster 26 & 25 & $13: 48$ & $25 \mathrm{~min}$ & $14: 27$ & $14: 26$ & -1 \\
\hline 18-3-14 & & & & 28 & $13: 50$ & & & & \\
\hline (INVVK) & & & & 33 & $14: 02$ & & & & \\
\hline
\end{tabular}


Table 5 (continued)

\begin{tabular}{|c|c|c|c|c|c|c|c|c|c|}
\hline $\begin{array}{l}\text { Radar/date } \\
\text { (region) }\end{array}$ & Time (UTC) & $\begin{array}{l}\text { Range/azi- } \\
\text { muth }\end{array}$ & Cluster no. & $\begin{array}{l}\text { Reflectivity } \\
(\mathrm{dBZ}) Z_{1} \\
Z_{2}, Z_{3}\end{array}$ & $\begin{array}{l}\text { Time } \\
\text { (UTC) } T_{1} \text {, } \\
T_{2}, T_{3}\end{array}$ & $\begin{array}{l}\text { Reac- } \\
\text { tion time } \\
\text { computed } \\
\text { as per PHDA } \\
\left(T_{4}-T_{3}\right)\end{array}$ & $\begin{array}{l}\text { Expected } \\
\text { hailstorm } \\
\text { occur- } \\
\text { rence time } \\
\left(T_{3}+\text { col. } 7\right)\end{array}$ & $\begin{array}{l}\text { Actual } \\
\text { occurrence } \\
\text { (when } \\
\text { reflectivity } \\
\text { actually } \\
\text { reached } \\
45 \mathrm{dBZ} \text { in } \\
\text { radar obser- } \\
\text { vation) }\end{array}$ & $\begin{array}{l}\text { Difference } \\
\text { (actual- } \\
\text { expected) in } \\
\text { minute }\end{array}$ \\
\hline 1 & 2 & 3 & 4 & 5 & 6 & 7 & 8 & 9 & 10 \\
\hline \multirow{3}{*}{$\begin{array}{l}\text { MUM- } \\
\text { BAl/18-3-14 } \\
\text { (Satara) }\end{array}$} & \multirow[t]{3}{*}{$13: 26$} & \multirow[t]{3}{*}{$220 \mathrm{~km} / 140^{\circ}$} & \multirow[t]{3}{*}{ Cluster 27} & 24 & $13: 26$ & \multirow[t]{3}{*}{ Null } & \multirow{3}{*}{$\begin{array}{l}\text { No hail- } \\
\text { storm }\end{array}$} & \multirow{3}{*}{$\begin{array}{c}\text { No hail- } \\
\text { storm }\end{array}$} & \multirow[t]{3}{*}{0} \\
\hline & & & & 28 & $13: 38$ & & & & \\
\hline & & & & 30 & $13: 50$ & & & & \\
\hline \multirow{3}{*}{$\begin{array}{l}\text { MUM- } \\
\text { BAl/18-3-14 } \\
\text { (RTN) }\end{array}$} & \multirow[t]{3}{*}{$15: 02$} & \multirow{3}{*}{$220 \mathrm{~km} / 160^{\circ}$} & \multirow[t]{3}{*}{ Cluster 28} & 23 & $15: 02$ & \multirow[t]{3}{*}{ Null } & \multirow{3}{*}{$\begin{array}{l}\text { No hail- } \\
\text { storm }\end{array}$} & \multirow{3}{*}{$\begin{array}{c}\text { No hail- } \\
\text { storm }\end{array}$} & \multirow{3}{*}{0} \\
\hline & & & & 27 & $15: 14$ & & & & \\
\hline & & & & 29 & $15: 26$ & & & & \\
\hline \multirow{3}{*}{$\begin{array}{l}\text { MUM- } \\
\text { BAl/18-3-14 } \\
\text { (DPL) }\end{array}$} & \multirow[t]{3}{*}{$14: 14$} & \multirow[t]{3}{*}{$130 \mathrm{~km} / 170^{\circ}$} & \multirow[t]{3}{*}{ Cluster 29} & 26 & $14: 14$ & \multirow[t]{3}{*}{ Null } & \multirow{3}{*}{$\begin{array}{l}\text { No hail- } \\
\text { storm }\end{array}$} & \multirow{3}{*}{$\begin{array}{c}\text { No hail- } \\
\text { storm }\end{array}$} & \multirow[t]{3}{*}{0} \\
\hline & & & & 29 & $14: 26$ & & & & \\
\hline & & & & 32 & $14: 38$ & & & & \\
\hline
\end{tabular}

in influencing the skill scores of hail prediction and reaction time values.

\subsection{PHDA validation for hail prediction}

Prediction skill score used in the present study is defined as the ratio of 'correct predictions' to the 'total predictions made' $^{\prime}$ (correct prediction/total predictions made). Tables 1,2 and 3 exhibit the skill score for $D_{10}^{5}, D_{12}^{12}$ and $D_{19}^{8}$, respectively.

In Tables 1,2 and 3, actual occurrences are shown in left column, and predictions made by PHDA are shown on the top row. In Table 1, with 10-min scan interval data, 6 times predictions were made for the occurrence of the hailstorm, whereas it really occurred 5 times. On one occassion hailstorm did not occur despite its prediction. Similarly, out of 13 predictions of non-occurrence of hailstorm 10 times it did not occur but 3 times it did occur. Diagonal values represent correct forecast. Hence, out of 19 predictions 15 were correct. Therefore, the skill score $=15 / 19=.79$. Similar explanations are given for Tables 2 and 3. It may be observed that the skill scores for $D_{10}^{5}, D_{12}^{12}$ and $D_{19}^{8}$ are $0.79,0.79$ and 0.75 , respectively. Skill scores for $D_{10}^{5}$ and $D_{12}^{12}$ are better than $D_{19}^{8}$, indicating that shorter time interval improvises the PHDA hail prediction accuracy.

\subsection{Prediction of reaction time (RT) by PHDA}

Tables 4, 5 and 6 exhibit the reaction time (RT) computation for data sets $D_{10}^{5}, D_{12}^{12}$ and $D_{19}^{8}$, respectively.

Mean (standard deviation) of the computed reaction time for $D_{10}^{5}, D_{12}^{12}$ and $D_{19}^{8}$ is 24 (8.95), 23.4 (6.15) and 26.3 (13), respectively. It is observed that for $D_{19}^{8}$ there is wide scatter of computed mean RT values of order of $13 \mathrm{~min}$. This indicates wide variation in the rate of growth on the 8 hailstorms in this data set. Also if the cumulus growth showed significant change in reflectivity with in less than $19 \mathrm{~min}$, then the process would not be captured in $D_{19}^{8}$. Hence, more reliable data set in the present sample is with shorter scan time, i.e. $D_{10}^{5}$ and $D_{12}^{12}$. Albeit the mean reaction time in both these data sets is almost same, higher number of hailstorms (12) and low standard deviation (6.15) indicates at more reliable range for the reaction time (Mean $\pm \sigma$ ), e.g. 17.3-29.6 min.

Minimum/maximum RT values in $D_{10}^{5}, D_{12}^{12}$ and $D_{19}^{8}$ are $16 / 43,14 / 39$ and $18 / 39$, respectively. Maximum RT of $43 \mathrm{~min}$ is predicted by $D_{10}^{5}$; it is an indication that some slow-growing cumulus can provide reasonably large reaction time of $43 \mathrm{~min}$ for conducting the seeding operation.

In Tables 4, 5 and 6, column 6 shows the difference between actual occurrence and the predicted time of occurrence. Hence, positive difference would indicate 
Table 6 Reaction time estimation $D_{19}^{8}$

\begin{tabular}{|c|c|c|c|c|c|c|c|c|c|}
\hline $\begin{array}{l}\text { Radar/date } \\
\text { (region) }\end{array}$ & Time (UTC) & $\begin{array}{l}\text { Range/azi- } \\
\text { muth }\end{array}$ & Cluster no. & $\begin{array}{l}\text { Reflectivity } \\
\text { (dBZ) } Z_{1} \\
Z_{2}, Z_{3}\end{array}$ & $\begin{array}{l}\text { Time } \\
\left(\text { UTC) } T_{1},\right. \\
T_{2}, T_{3}\end{array}$ & $\begin{array}{l}\text { Reac- } \\
\text { tion time } \\
\text { computed } \\
\text { as per PHDA } \\
\left(T_{4}-T_{3}\right)\end{array}$ & $\begin{array}{l}\text { Expected } \\
\text { hailstorm } \\
\text { occur- } \\
\text { rence time } \\
\left(T_{3}+\text { col. } 7\right)\end{array}$ & $\begin{array}{l}\text { Actual occur- } \\
\text { rence (when } \\
\text { reflectivity } \\
\text { actually } \\
\text { reached } \\
45 \mathrm{dBZ} \text { in } \\
\text { radar obser- } \\
\text { vation) }\end{array}$ & $\begin{array}{l}\text { Difference } \\
\text { (actual- } \\
\text { expected) in } \\
\text { minute }\end{array}$ \\
\hline 1 & 2 & 3 & 4 & 5 & 6 & 7 & 8 & 9 & 10 \\
\hline \multirow{3}{*}{$\begin{array}{l}\text { MUM- } \\
\text { BAI/2-6-13 } \\
\text { (Nasik) }\end{array}$} & \multirow[t]{3}{*}{$8: 00$} & \multirow[t]{3}{*}{$210 \mathrm{~km} / 42^{\circ}$} & \multirow[t]{3}{*}{ Cluster 1} & 24 & $8: 00$ & \multirow[t]{3}{*}{$18 \mathrm{~min}$} & \multirow[t]{3}{*}{$8: 56$} & \multirow[t]{3}{*}{$8: 57$} & \multirow[t]{3}{*}{-1} \\
\hline & & & & 32 & $8: 19$ & & & & \\
\hline & & & & 40 & $8: 38$ & & & & \\
\hline \multirow{3}{*}{$\begin{array}{l}\text { MUM- } \\
\text { BAI/2-6-13 } \\
\text { (near to } \\
\text { Nasik) }\end{array}$} & \multirow[t]{3}{*}{$8: 19$} & \multirow[t]{3}{*}{$175 \mathrm{~km} / 48^{\circ}$} & \multirow[t]{3}{*}{ Cluster 2} & 29 & $8: 19$ & \multirow[t]{3}{*}{ Null } & \multirow[t]{3}{*}{ No hailstorm } & \multirow[t]{3}{*}{ No hailstorm } & \multirow[t]{3}{*}{0} \\
\hline & & & & 37 & $8: 38$ & & & & \\
\hline & & & & 41 & $8: 57$ & & & & \\
\hline \multirow{3}{*}{$\begin{array}{l}\text { MUM- } \\
\text { BAI/2-6-13 } \\
(\mathrm{AHW})\end{array}$} & \multirow[t]{3}{*}{$8: 19$} & \multirow[t]{3}{*}{$200 \mathrm{~km} / 33^{\circ}$} & \multirow[t]{3}{*}{ Cluster 3} & 29 & $8: 19$ & \multirow[t]{3}{*}{$30 \mathrm{~min}$} & \multirow[t]{3}{*}{$9: 27$} & \multirow[t]{3}{*}{$9: 35$} & \multirow[t]{3}{*}{8} \\
\hline & & & & 32 & $8: 38$ & & & & \\
\hline & & & & 35 & $8: 57$ & & & & \\
\hline \multirow{3}{*}{$\begin{array}{l}\text { MUM- } \\
\text { BAI/2-6-13 } \\
\text { (Nasik) }\end{array}$} & $9: 35$ & $230 \mathrm{~km} / 345^{\circ}$ & Cluster 4 & 26 & $9: 35$ & $24 \mathrm{~min}$ & $10: 37$ & $10: 32$ & -5 \\
\hline & & & & 34 & $9: 54$ & & & & \\
\hline & & & & 41 & $10: 13$ & & & & \\
\hline MUM- & 9:35 & $150 \mathrm{~km} / 35^{\circ}$ & Cluster 5 & 23 & 9:35 & $24 \mathrm{~min}$ & $10: 37$ & $10: 40$ & 3 \\
\hline $\mathrm{BAI} / 2-6-13$ & & & & 29 & $9: 54$ & & & & \\
\hline & & & & 36 & $10: 13$ & & & & \\
\hline MUM- & $7: 41$ & $210 \mathrm{~km} / 142^{\circ}$ & Cluster 6 & 22 & $8: 57$ & Null & No hailstorm & $10: 13$ & 0 \\
\hline $\mathrm{BAl} / 2-6-13$ & & & & 41 & $9: 16$ & & & & \\
\hline & & & & 36 & $9: 35$ & & & & \\
\hline & $9: 54$ & $120 \mathrm{~km} / 60^{\circ}$ & Cluster 7 & 28 & 9:54 & $18 \mathrm{~min}$ & $11: 19$ & $11: 29$ & 9 \\
\hline $\mathrm{BAl} / 2-6-13$ & & & & 32 & $10: 32$ & & & & \\
\hline & & & & 41 & $10: 51$ & & & & \\
\hline MUM- & $16: 33$ & $200 \mathrm{~km} / 90^{\circ}$ & Cluster 8 & 23 & $16: 33$ & Null & No hailstorm & $18: 27$ & 0 \\
\hline $\mathrm{BAI} / 2-6-13$ & & & & 32 & $16: 52$ & & & & \\
\hline $\begin{array}{l}\text { (Anemad- } \\
\text { nagar) }\end{array}$ & & & & 34 & $17: 11$ & & & & \\
\hline MUM- & 9:39 & $220 \mathrm{~km} / 85^{\circ}$ & Cluster 9 & 22 & $9: 39$ & Null & No hailstorm & $10: 36$ & 0 \\
\hline $\mathrm{BAI} / 3-6-13$ & & & & 33 & $9: 58$ & & & & \\
\hline nagar & & & & 23 & $10: 17$ & & & & \\
\hline MUM- & 9:35 & $240 \mathrm{~km} / 45^{\circ}$ & Cluster 10 & 23 & $9: 35$ & $39 \mathrm{~min}$ & $10: 52$ & $10: 51$ & -1 \\
\hline BAI/6-6-13 & & & & 29 & $9: 54$ & & & & \\
\hline nagar) & & & & 33 & $10: 13$ & & & & \\
\hline MUM- & $9: 21$ & $130 \mathrm{~km} / 100^{\circ}$ & Cluster 11 & 24 & $9: 21$ & $26 \mathrm{~min}$ & $10: 25$ & $10: 56$ & 31 \\
\hline BAI/8-6-13 & & & & 29 & $9: 40$ & & & & \\
\hline & & & & 35 & $9: 59$ & & & & \\
\hline MUM- & $12: 50$ & $210 \mathrm{~km} / 85^{\circ}$ & Cluster 12 & 24 & $12: 50$ & $32 \mathrm{~min}$ & $14: 00$ & $13: 47$ & -13 \\
\hline BAI/8-6-13 & & & & 32 & 13:09 & & & & \\
\hline $\begin{array}{l}\text { (Anemad- } \\
\text { nagar) }\end{array}$ & & & & 38 & $13: 28$ & & & & \\
\hline
\end{tabular}


Table 7 Speed of cumulus for $D_{10}^{5}$

\begin{tabular}{llll}
\hline $\begin{array}{l}\text { Cloud cluster } \\
\text { no. }\end{array}$ & $\begin{array}{l}\text { Estimated } \\
\text { speed } \\
\text { By PHDA algo- } \\
\text { rithm }\end{array}$ & $\begin{array}{l}\text { Actual } \\
\text { Speed as } \\
\text { observed by } \\
\text { radar }\end{array}$ & Col. 3-Col. 2 \\
Column-1 & Column-2 & Column-3 & Column-4 \\
\hline 1 & 11.5 & 15.5 & 4 \\
2 & 11.5 & 8.56 & -2.94 \\
3 & 27 & 19.3 & -7.7 \\
4 & 16.3 & 14.58 & -1.72 \\
5 & 10.83 & 9.15 & -1.68 \\
6 & 14.1 & 11.2 & -2.9 \\
7 & 14.4 & 12.45 & -1.95 \\
8 & 8.66 & 12.33 & 3.67 \\
9 & 8.83 & 8.2 & -0.63 \\
10 & 15.33 & 14.85 & -0.48 \\
11 & 12 & 11.75 & -0.25 \\
12 & 13.23 & 11.89 & -1.34 \\
\hline
\end{tabular}

Table 8 Speed of cumulus for $D_{12}^{2}$

\begin{tabular}{|c|c|c|c|}
\hline \multirow[t]{3}{*}{$\begin{array}{l}\text { Cloud cluster } \\
\text { no. }\end{array}$} & $\begin{array}{l}\text { Estimated } \\
\text { speed }\end{array}$ & Actual & Actual-expected \\
\hline & $\begin{array}{l}\text { By PHDA algo- } \\
\text { rithm }\end{array}$ & $\begin{array}{l}\text { Speed as } \\
\text { observed by } \\
\text { radar }\end{array}$ & Col. 3-Col. 2 \\
\hline & $(\mathrm{m} / \mathrm{s})$ & $(\mathrm{m} / \mathrm{s})$ & $(\mathrm{m} / \mathrm{s})$ \\
\hline Column 1 & Column 2 & Column 3 & Column 4 \\
\hline 1 & 8.61 & 9 & 0.39 \\
\hline 2 & 12.4 & 12 & -0.4 \\
\hline 3 & 13.31 & 16.4 & 3.09 \\
\hline 4 & 16 & 19.34 & 3.34 \\
\hline 5 & 9.1 & 13 & 3.9 \\
\hline 6 & 7.23 & 8.1 & 0.87 \\
\hline 7 & 6.4 & 6 & -0.4 \\
\hline 8 & 13.47 & 11 & -2.47 \\
\hline 9 & 6.5 & 8 & 1.5 \\
\hline 10 & 12 & 8.34 & -3.66 \\
\hline 11 & 11.39 & 10.2 & -1.19 \\
\hline 12 & 12.1 & 9.5 & -2.6 \\
\hline
\end{tabular}

PHDA erring on operationally safe side as actual time available for the completion of seeding operation is more than the planned one. Based on the $D_{10}^{5}, D_{12}^{12}$ and $D_{19}^{8}$ data sets, the mean (standard deviation) of positive errors is $8(8.3)$ and that of negative errors is 5.15 (4.7). Negative error differences are worrisome from operational safety point of view. It ranges from 1 to $13 \mathrm{~min}$ in all data sets. In $D_{10}^{5}$, the maximum negative value is $8 \mathrm{~min}$, whereas in $D_{12}^{12}$ and $D_{19}^{8}$
Table 9 Speed of cumulus for $D_{19}^{8}$

\begin{tabular}{llll}
\hline $\begin{array}{l}\text { Cloud cluster } \\
\text { no. }\end{array}$ & $\begin{array}{l}\text { Estimated } \\
\text { speed } \\
\text { By PHDA algo- } \\
\text { rithm }\end{array}$ & $\begin{array}{l}\text { Actual } \\
\text { Speed as } \\
\text { observed by } \\
\text { radar } \\
\text { (m/s) }\end{array}$ & Col. 3-Col. 2 \\
Column 1 & Column 2 & Column 3 & Column 4 \\
\hline 1 & 15.66 & 14.85 & -0.81 \\
2 & 9.56 & 10 & 0.46 \\
3 & 5 & 6 & 1 \\
4 & 5.22 & 6 & 0.78 \\
5 & 4.83 & 5.65 & 0.82 \\
6 & 9.88 & 10 & 0.22 \\
7 & 8.12 & 8 & -0.12 \\
8 & 7.16 & 9 & 1.84 \\
9 & 6.5 & 5 & -1.5 \\
10 & 14.66 & 18 & 3.34 \\
\hline
\end{tabular}

it is $13 \mathrm{~min}$. Hence, from operational safety point of view 10-min scan interval is safer for prediction of reaction time by PHDA based on the present sample of data.

\subsection{Prediction of cloud motion speed by PHDA}

Tables 7, 8 and 9 show the speed computation, based on the PHDA algorithm for 12 clusters each from $D_{10}^{5}, D_{12}^{12}$ and $D_{19}^{8}$, respectively.

It may be noted that mean (standard deviation) of the anomalies from the predicted speed in Tables 7, 8 and 9 is $1.16(3.0), 0.12$ (2.5) and 0.7 (1.2), respectively. Although it indicates good accuracy in the predicted speed in all the three data sets, the lowest value of standard deviation of anomalies in prediction is obtained in Table 9. This could indicate that accuracy of speed computation through PHDA algorithm could improve with larger scan time data.

As the data in Tables 7, 8 and 9 have been collected from different places of India, there is a wide variation in cluster speed ranging from $5 \mathrm{~m} / \mathrm{s}$ to as high as $19.3 \mathrm{~m} / \mathrm{s}$. This could be due to the regional and seasonal variability in the upper wind conditions in the Indian subcontinent.

\section{Example case on how to use PHDA}

In this section, four example cases, two each from $D_{10}^{5}$ and $D_{19}^{8}$, are presented as illustration for occurrence and non-occurrence cases of hailstorm, correctly predicted 


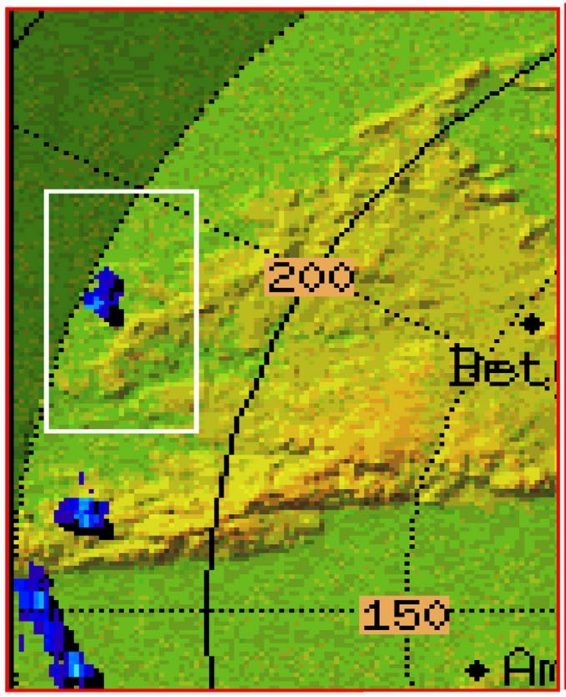

(a)

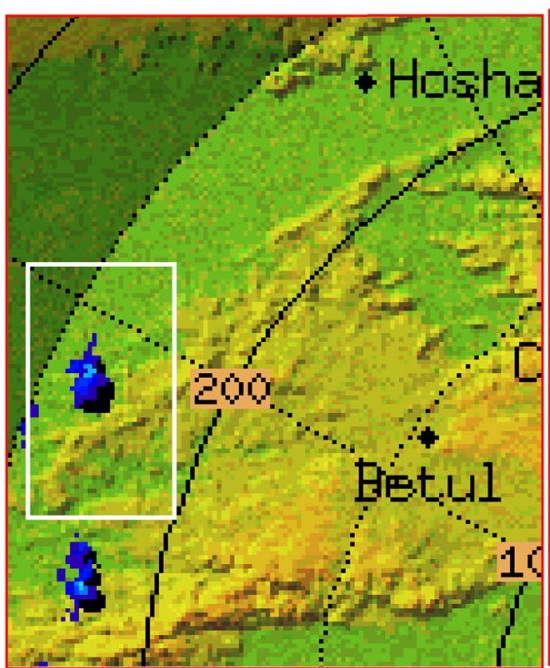

(c)

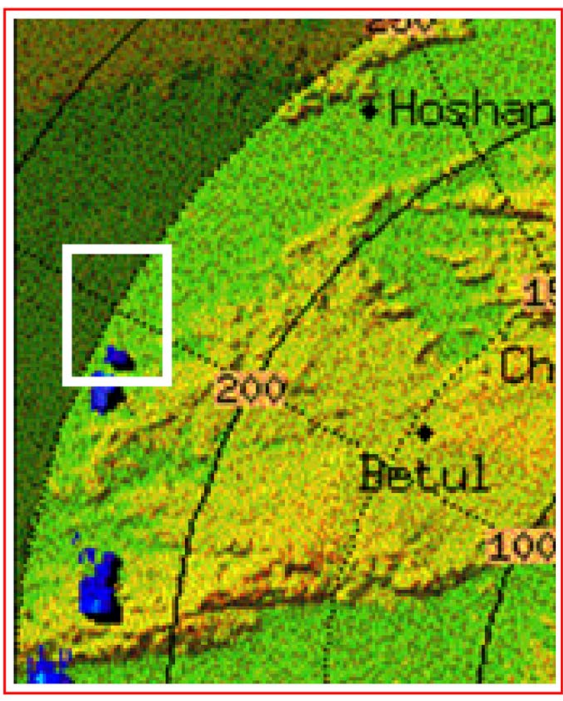

(b)

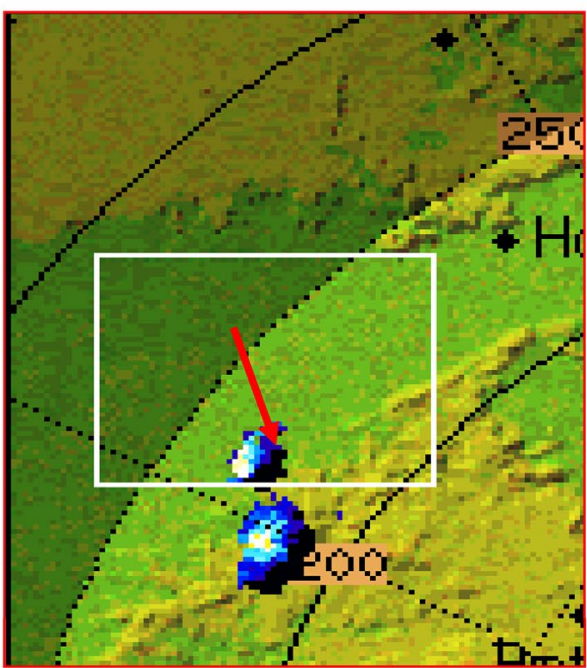

(d)

\begin{tabular}{|c|c|}
\hline & \\
\hline 57,3 & $>60,0$ \\
\hline 54.7 & 57,3 \\
\hline 52.0 & 54,7 \\
\hline 49.3 & 52,0 \\
\hline 46.7 & 49.37 \\
\hline 44,0 & $46,7 ?$ \\
\hline 41,3 & 44,0 \\
\hline 38.7 & 41,3 \\
\hline 36,0 & 38,7 \\
\hline $\begin{array}{l}33,3 \\
70,7\end{array}$ & 36,0 \\
\hline $\begin{array}{l}30.7 \\
28 .\end{array}$ & $\begin{array}{l}3,3 \\
30.7\end{array}$ \\
\hline 25.3 & 28,0 \\
\hline 22,7 & 25,3 \\
\hline 20,0 & 22,7 \\
\hline
\end{tabular}

Fig. 5 (16 Mar 2013, Mumbai). a Cluster inside the rectangular shed with reflectivity: $21 \mathrm{dBZ}$, range: $245 \mathrm{~km}$, Azimuth: $290^{\circ}$ (4:10 Z UTC). b Cluster inside the rectangular shed with reflectivity: $23 \mathrm{dBZ}$, range: $242 \mathrm{~km}$, Azimuth: $292^{\circ}$ (4:20 Z UTC). c Cluster inside the rectangular shed with reflectivity: $27 \mathrm{dBZ}$, range: $235 \mathrm{~km}$, azimuth:

by QGH. Graphical extrapolation of the quadratic curve will guide readers on how the hypothesis works.

\subsection{Example from $D_{10}^{5}$}

\subsubsection{Occurrence of hailstorm}

Nagpur radar pictures of 16 March 2013 taken from $D_{10}^{5}$ are shown in Fig. 5 (cluster 1). Growth of cluster, marked inside rectangle, may be noted. Figure 5 a shows the spotting of specific cluster having a very low reflectivity $295^{\circ}$ (4:30 Z UTC). d Cluster inside the rectangular shed with reflectivity: $45 \mathrm{dBZ}$, range: $235 \mathrm{~km}$, azimuth: $305^{\circ}$ (5:10 Z UTC). Note small speck of light yellow colour close to the head of arrow, within the rectangle

value ( $21 \mathrm{dBZ}$ ). The rectangular shed in Fig. $5 \mathrm{~b}$ shows the tracking of same cluster with increased reflectivity of $23 \mathrm{dBZ}$. Figure $5 \mathrm{c}$ shows the same cluster which has moved to different positions with reflectivity of $27 \mathrm{dBZ}$. Figure $5 \mathrm{~d}$ shows the occurrence of hailstorm at around 5:10 UTC. Note small speck of light yellow as indicated by arrow head within the rectangle. Prediction based on Pre Hail Detection Algorithm indicates hailstorm occurs at 4:57 UTC and positive error of $13 \mathrm{~min}$. Predicted reaction time was $27 \mathrm{~min}$. 


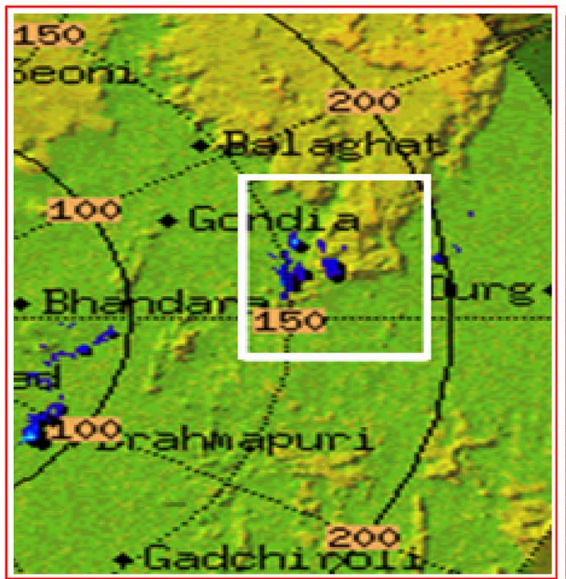

(a)

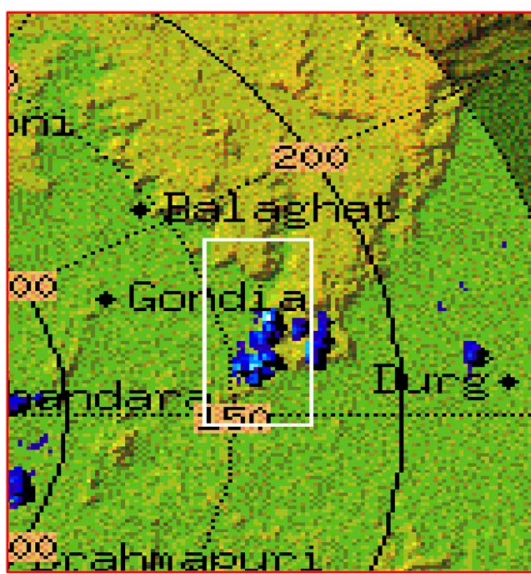

(c)

Fig. 6 (16 Mar 2013, Mumbai). a Cluster inside the rectangular shed with reflectivity: $22 \mathrm{dBZ}$, range: $160 \mathrm{~km}$, azimuth: $85^{\circ}$ (4:10 Z UTC). b Cluster inside the rectangular shed with reflectivity: $26 \mathrm{dBZ}$, range: $165 \mathrm{~km}$, azimuth: $80^{\circ}$ (4:20 Z UTC). c Cluster inside the rectangular shed with reflectivity: $29 \mathrm{dBZ}$, range: $166 \mathrm{~km}$, azimuth: $78^{\circ}$

It may be observed that rate of growth $(r)$ during first $10 \mathrm{~min}$ and next $10 \mathrm{~min}$ was moderate as $r=0.5$ and 0.4 , respectively.

\subsubsection{Non-occurrence of hailstorm}

Another cloud cluster of Nagpur radar picture of 16 March 2012 is spotted and tracked in Fig. 6a-c (cluster 3). This cluster did not show any significant growth in its reflectivity. From Fig. $6 a-c$, the PHDA finds complex roots and hence predicts for non-occurrence.

Figure $6 \mathrm{~d}$ shows that although the specific cluster's reflectivity is increasing still, the extrapolated quadratic curve does not cut the 45-dBZ abscissa. QGH equation is shown in Fig. $6 \mathrm{~d}$. So the cloud was predicted as not
(4:30 Z UTC). d Graphical representation of quadratic extrapolation. 45-dBZ ordinates are not intersected. Quadratic equation is shown in the figure. It predicts no hailstorm. $X$-axis is time interval in minutes, and $y$-axis is the reflectivity in $\mathrm{dBZ}$ units

having potential of a hail forming cloud. The observation matched with the PHDA prediction.

Rate of growth $(r)$ during first $10 \mathrm{~min}$ and next $10 \mathrm{~min}$ was moderate as $r=0.4$ and 0.3 , respectively.

\subsection{Example from $D_{19}^{8}$}

\subsubsection{Occurrence of hailstorm}

Mumbai radar imageries of 2 June 2013 are shown in Fig. $7 \mathrm{a}-\mathrm{c}$ at 19-min interval each. Prediction based on quadratic extrapolation is shown in Fig. 7. QGH predicts the occurrence of hailstorm as the extrapolated curve cuts the $45-d B Z$ ordinate. 


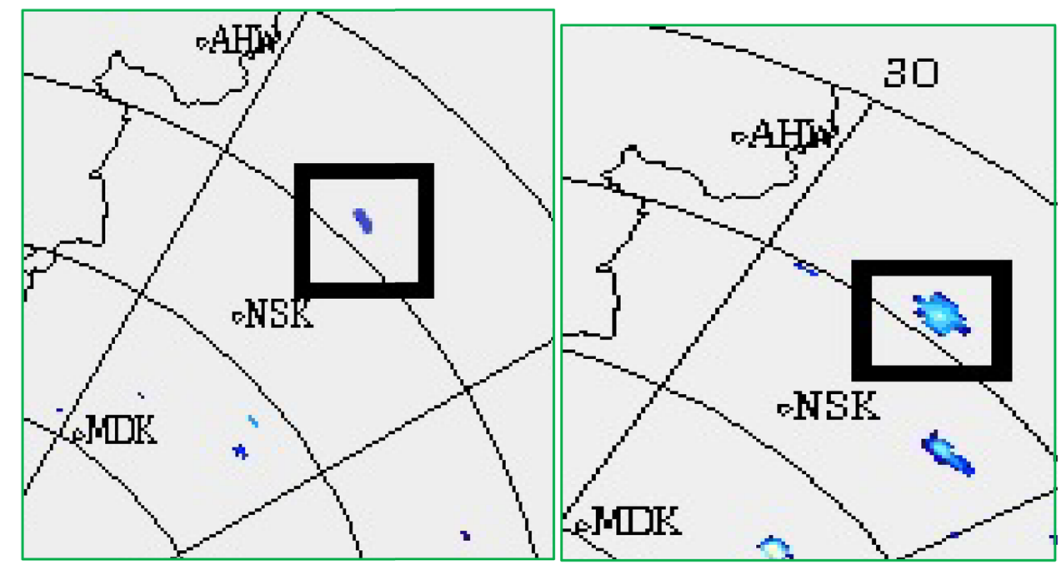

(a) '(b)

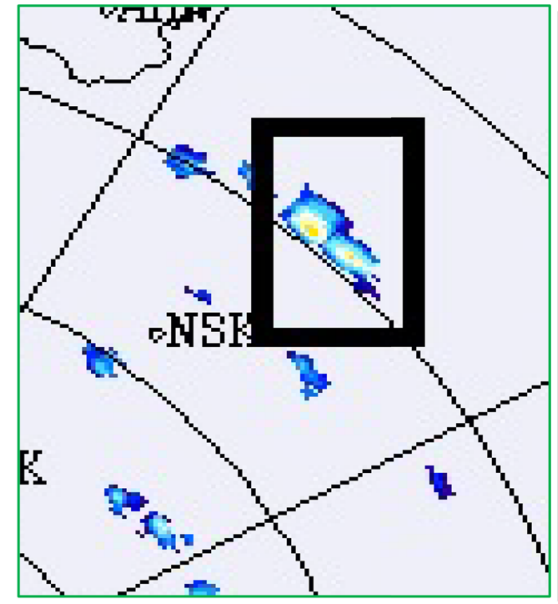

(c)

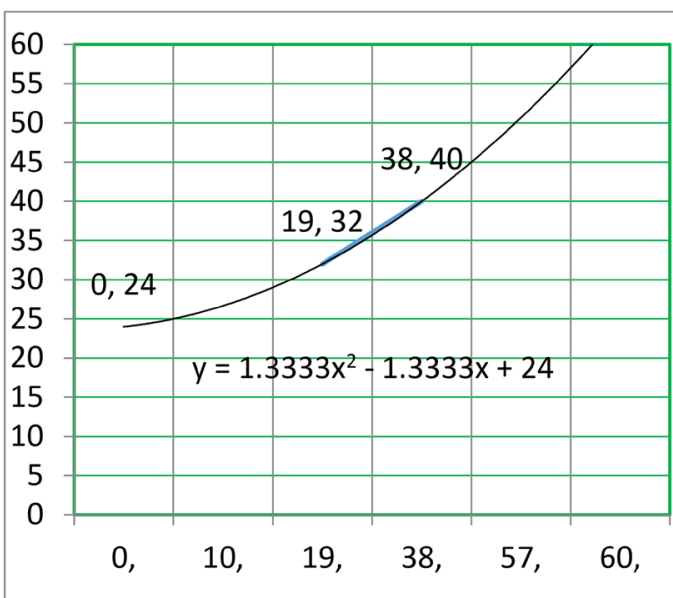

(d)
Fig. 7 (02 Jun 2013, Mumbai). a Cluster inside the rectangular shed with reflectivity: $24 \mathrm{dBZ}$, range: $210 \mathrm{~km}$, azimuth: $42^{\circ}(8: 00 \mathrm{Z}$ UTC). $\mathbf{b}$ Cluster inside the rectangular shed with reflectivity: $32 \mathrm{dBZ}$, range: $205 \mathrm{~km}$, azimuth: $48^{\circ}$ (8:19 Z UTC). c Cluster inside the rectangular shed with reflectivity: $40 \mathrm{dBZ}$, range: $203 \mathrm{~km}$, azimuth: $55^{\circ}$
(8:38 Z UTC). d Graphical representation of quadratic extrapolation. 45-dBZ ordinates are intersected after certain interval of time. Quadratic equation is shown in the figure. It predicts hailstorm. $X$-axis is time interval in minutes, and $y$-axis is the reflectivity in $\mathrm{dBZ}$ units
Rate of growth $(r)$ during first $19 \mathrm{~min}$ and next $19 \mathrm{~min}$ was moderate as $r=0.42$ and 0.42 , respectively. Figure $7 \mathrm{~d}$ shows quadratic equation based on $\mathrm{QGH}$.

\subsubsection{Non-occurrence of hailstorm}

Mumbai radar imageries of 2 June 2013 with cluster 2, mentioned in Table 5, are shown in Fig. 8a-c. Although the reflectivity grew from 29 to $41 \mathrm{dBZ}$ in the interval of $38 \mathrm{~min}$, PHDA predicted no hailstorm. It was also verified as correct by actual radar observation.

Graphical analysis shown in Fig. 8d also infers no hailstorm since extrapolated quadratic curve does not cut the $45-\mathrm{dBZ}$ ordinate. Rate of growth $(r)$ during first $19 \mathrm{~min}$ and next 19 min was moderate as $r=0.42$ and 0.26 , respectively.

\section{Cases which could not be predicted by PHDA}

Four cases were abnormal with slow followed by fast growth or reversal of reflectivity values. These cases could not be correctly predicted by PHDA. They are discussed clusterwise, below: 


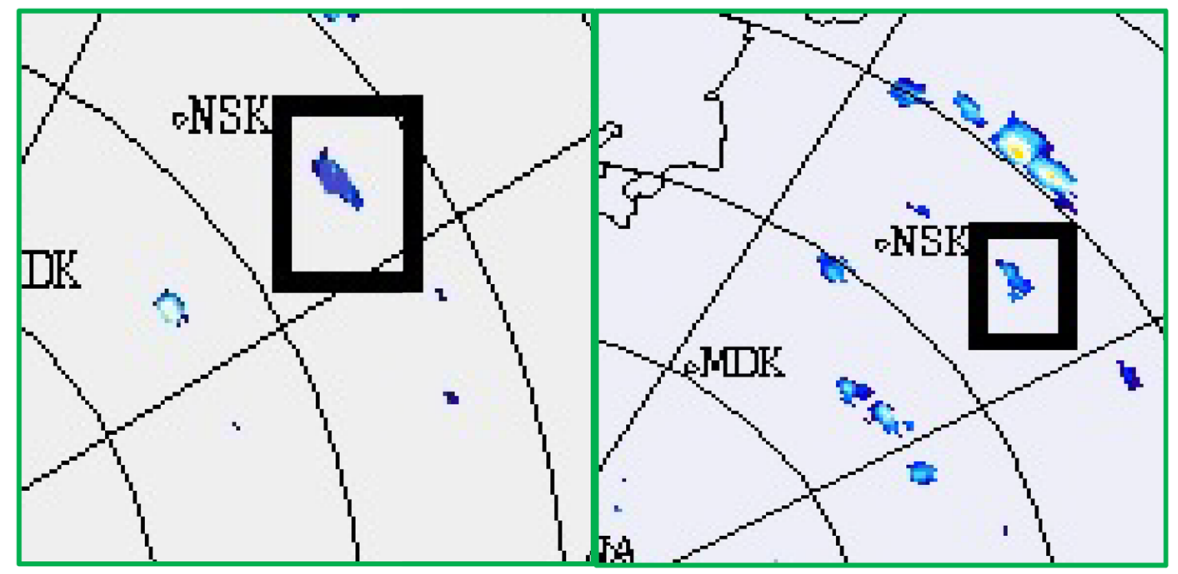

(a)

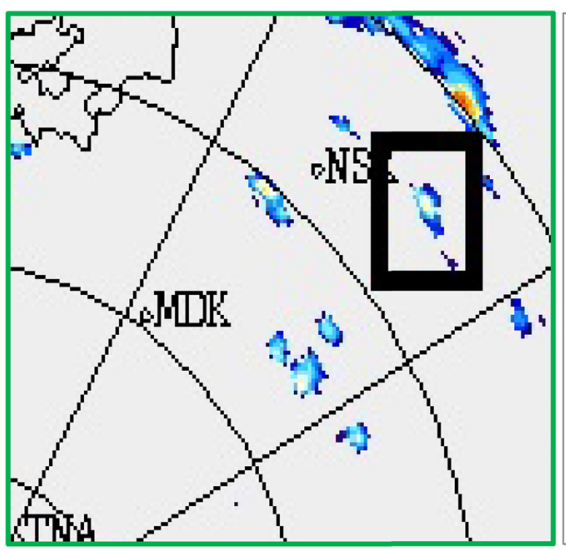

(c) (b)

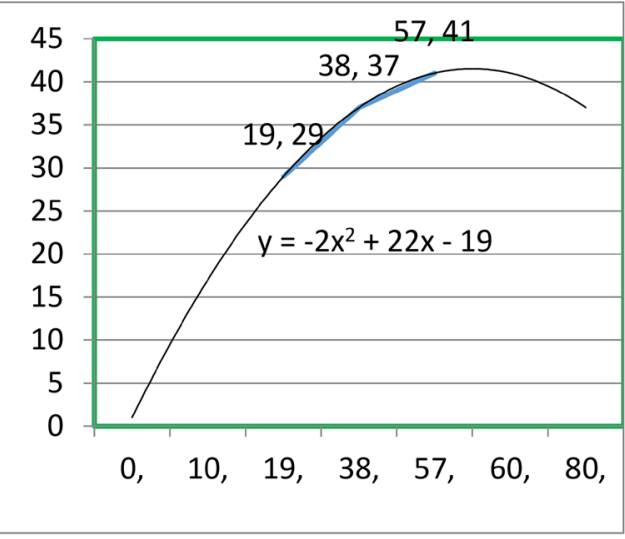

(d)

\begin{tabular}{|c|c|}
\hline 57,3 & 760,0 \\
\hline 54,7 & 57,3 \\
\hline 52,0 & 54,7 \\
\hline 49,3 & 52,0 \\
\hline 46.7 & 49,3 \\
\hline 44,0 & 46.7 \\
\hline 41,3 & 44,0 \\
\hline 38,7 & 41,3 \\
\hline 36,0 & 30,7 \\
\hline 33,3 & 36,0 \\
\hline 30,7 & 33,3 \\
\hline 28,0 & 30.7 \\
\hline $\begin{array}{l}25.3 \\
97\end{array}$ & 28.0 \\
\hline & \\
\hline
\end{tabular}

Fig. 8 (02 Jun 2013, Mumbai). a Cluster inside the rectangular shed with reflectivity: $29 \mathrm{dBZ}$, range: $175 \mathrm{~km}$, azimuth: $48^{\circ}$ (8:19 Z UTC). $\mathbf{b}$ Cluster inside the rectangular shed with reflectivity: $37 \mathrm{dBZ}$, range: $173 \mathrm{~km}$, azimuth: $50^{\circ}$ (8:38 Z UTC). c Cluster inside the rectangular shed with reflectivity: $41 \mathrm{dBZ}$, range: $170 \mathrm{~km}$, azimuth: $55^{\circ}$
(8:57 Z UTC). d Graphical representation of quadratic extrapolation. 45- $\mathrm{dBZ}$ ordinates are not intersected. Quadratic equation is shown in the figure. It predicts no hailstorm. $X$-axis is time interval in minutes, and $y$-axis is the reflectivity in $\mathrm{dBZ}$ units

\subsection{Cluster 7, Table 4}

Nagpur radar imagery of 3 March 2016 indicated slow increase in reflectivity as $r=0.2$, from 26 to $28 \mathrm{dBZ}$ from 6:10 UTC to 6:20 UTC (Fig. 9a, b). In following ten minutes, the reflectivity suddenly jumped to $44 \mathrm{dBZ}$ at $6: 30$ UTC (Fig. 9d) with fast $r=1.6$.

In this case, PHDA predicted the occurrence of hailstorm. But contrary to the PHDA algorithm a fast reversal of cloud reflectivity was observed with $r_{n}=0.4$ making it to drop down to $40 \mathrm{dBZ}$ at 6:40 UTC (Fig. 9d). This is case of fast $r$ followed by fast $r_{n}$. An abnormal increase and decrease in cloud's reflectivity values were observed which could not be captured by PHDA algorithm.

\subsection{Cluster 6, Table 6}

Cloud cluster no. 6 on 2 June 2013 in Mumbai radar, spotted in $D_{19}^{8}$, is shown in Fig. 10a-d. It may be noted that the reflectivity abnormally grew fast $(r=1.0)$ from 22 to $41 \mathrm{dBZ}$ within 19 min followed by slow reversal in reflectivity $\left(r_{n}=0.26\right)$, in 


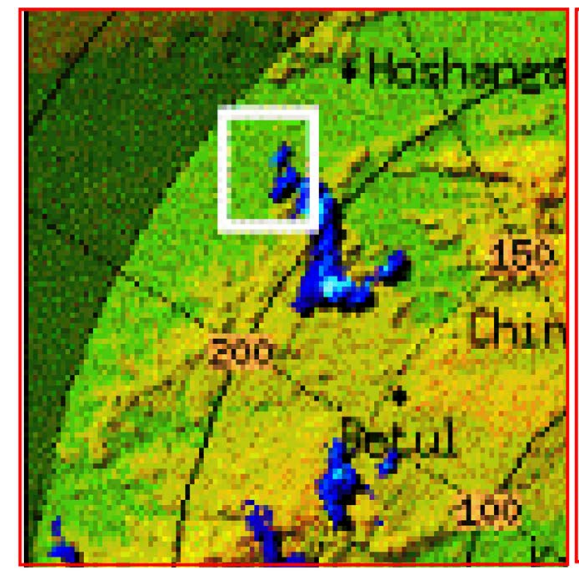

(a)

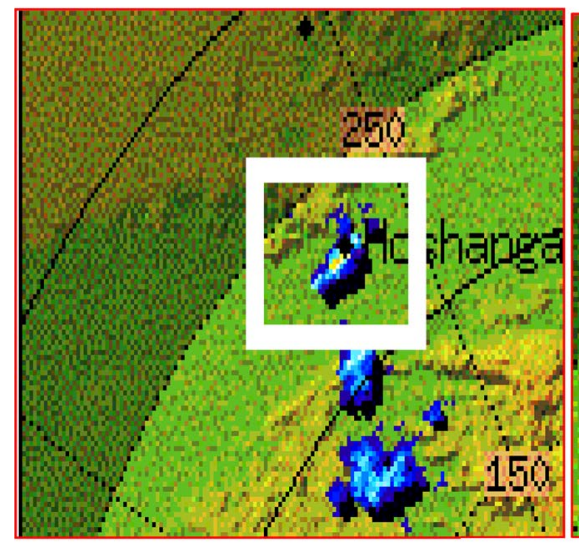

(c)

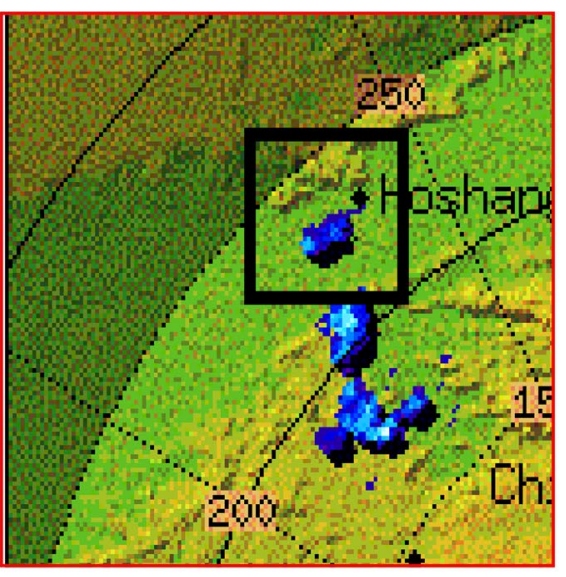

(b)

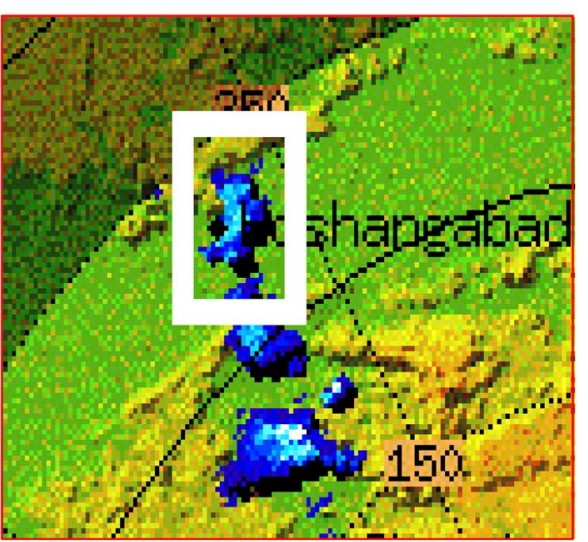

(d)

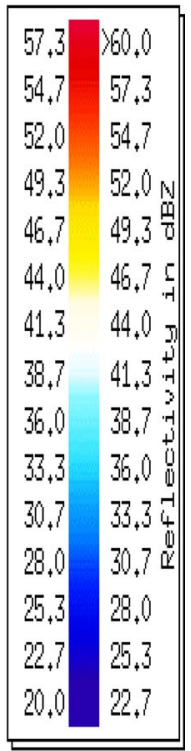

Fig. 9 (16 Mar 2013, Mumbai). a Cluster inside the rectangular shed with reflectivity: $26 \mathrm{dBZ}$ (6:10 Z UTC). b Cluster inside the rectangular shed with reflectivity: $28 \mathrm{dBZ}$ (6:20 Z UTC). c Cluster inside the

the next observation at 9:35 UTC which brought it down to $36 \mathrm{dBZ}$. This was the case of fast $r$ followed by slow $r_{n}$.

PHDA predicted no hailstorm, but hailstorm really occurred at 10:13 UTC as per the ground report.

\subsection{Cluster 8, Table 6}

Cloud cluster no. 8, spotted by Mumbai radar on 2 June 2013, is shown in Fig. 11a-d. In this case, there was moderate growth of reflectivity $(r=0.47)$ from 23 to $32 \mathrm{dBZ}$, but the rate of growth suddenly weakened in next 19 min at $r=0.1$. PHDA predicted no hailstorm, but hailstorm really occurred $76 \mathrm{~min}$ later at 18:27 UTC. This is the case of moderate $r$ followed by slow $r$. If 19-min scan interval was too long, missed out rectangular shed with reflectivity: $44 \mathrm{dBZ}$ (6:30 Z UTC). d Cluster inside the rectangular shed with reflectivity: $40 \mathrm{dBZ}$ (6:40 Z UTC)

short-term reflectivity changes may be further investigated to explore the incorrect prediction by PHDA.

\subsection{Cluster 9, Table 6}

Cloud cluster no. 9 was spotted on 3 June 2013 in Mumbai radar as shown in Fig. 12a-d. It may be observed that growth of reflectivity was moderate $(r=0.58)$ during initial $19 \mathrm{~min}$; then, it reversed back to fast decay $\left(r_{n}=0.52\right)$ in next $19 \mathrm{~min}$. PHDA predicted no hailstorm, but hailstorm actually occurred at 10:36 UTC, i.e. 19 min later. This was typical case of moderate $r$ followed by fast $r_{n}$. 


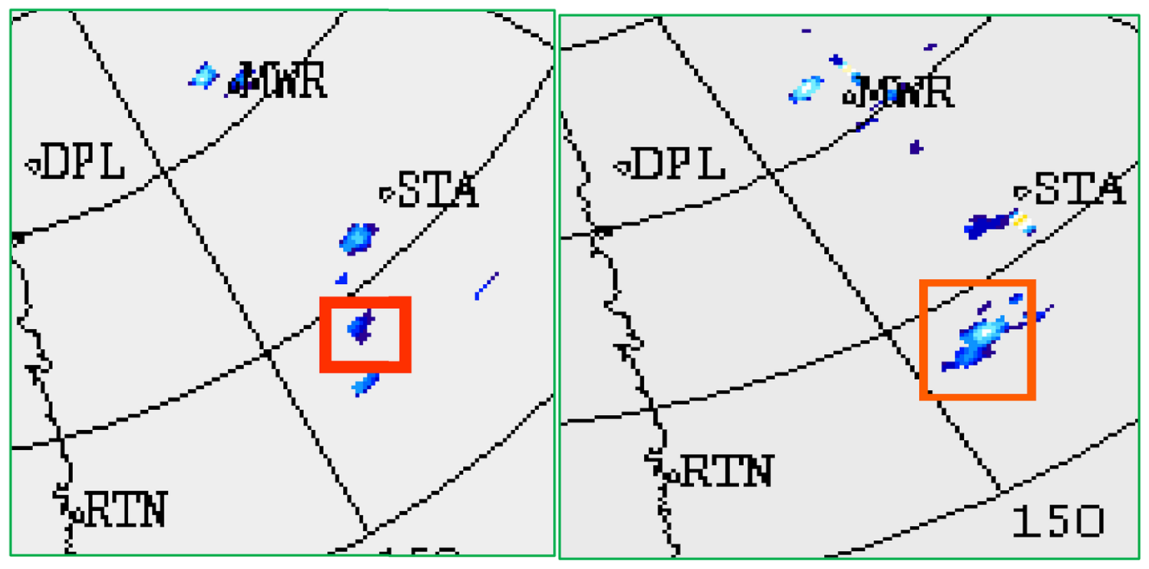

(a)

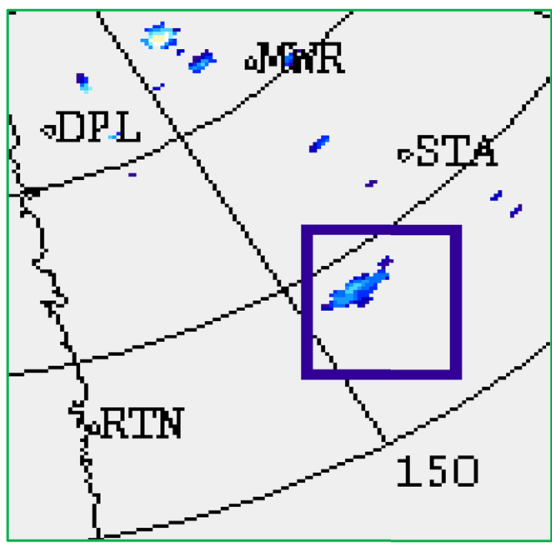

(c)

Fig. 10 (02 Jun 2013, Mumbai). a Cluster inside the rectangular shed with reflectivity: $22 \mathrm{dBZ}$ (8:57 Z UTC). b Cluster inside the rectangular shed with reflectivity: $41 \mathrm{dBZ}$ (9:16 Z UTC). c Cluster inside (b)

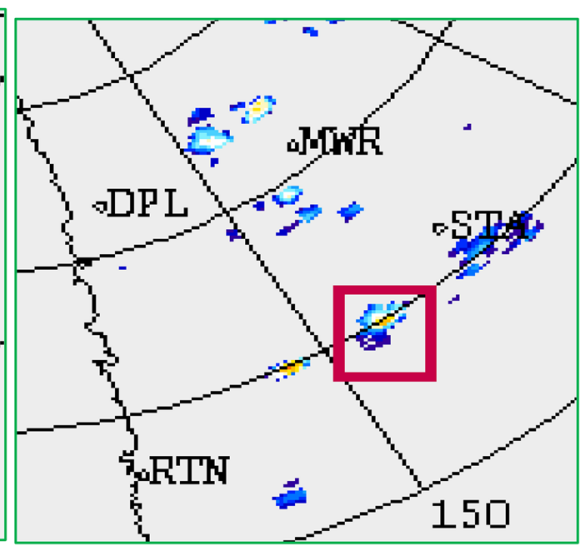

(d)

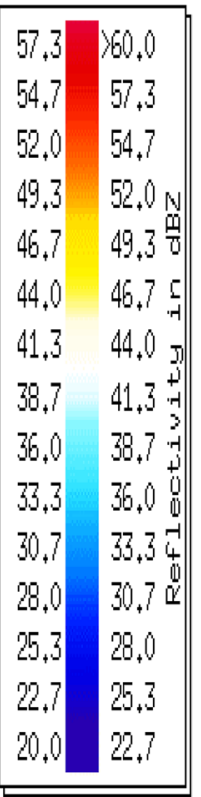

the rectangular shed with reflectivity: $36 \mathrm{dBZ}$ (9:35 Z UTC). d Cluster inside the rectangular shed with reflectivity: $41 \mathrm{dBZ}$ (10:13 Z UTC)

\section{Discussion}

\subsection{QGH-based algorithm}

Section 5 presents that QGH algorithm presents correct forecast for a few moderate-growing cumulus. Incorrect predictions in Sect. 6 were attributed to either 'slow followed by fast' or 'temporary reverse growth of cumuli'. To further analyse the relation between QGH and rate of growth of cumulus, a scatter diagram was plotted for correct and incorrect predictions verses rate of growth of cumulus. In Fig. 13, the rate of growth of cumulus between the first and second observations is plotted on $x$-axis and between the second and third observations is on $y$-axis. Blue and red dots correspond to correct and incorrect predictions, respectively, based on QGH. Mostly growth of cumulus significantly slows down as it becomes taller. Therefore, all the cases but for one lie on the right of $45^{\circ}$ slant line.

Large rectangle marked in Fig. 13 may be divided in two halves. QGH-based prediction is $100 \%$ correct in the left rectangle and $62.5 \%$ accurate in the right rectangle. Slowgrowing $(r \leq 0.2)$ cumulus are $100 \%$ correctly predicted by the QGH algorithm. Interestingly, Fig. 13 shows that all growing cumuli falling within the rectangle $0.45 \times 0.6$ appear to empirically follow QGH. Hence, it may be termed as 'QGH-Rectangle'. Although, to firmly authenticate the prediction, in future studies, it may verified for other regions, too, with larger data set. In two cases of reverse growth (two blue dots marked in 4th quadrant), too, QGH 


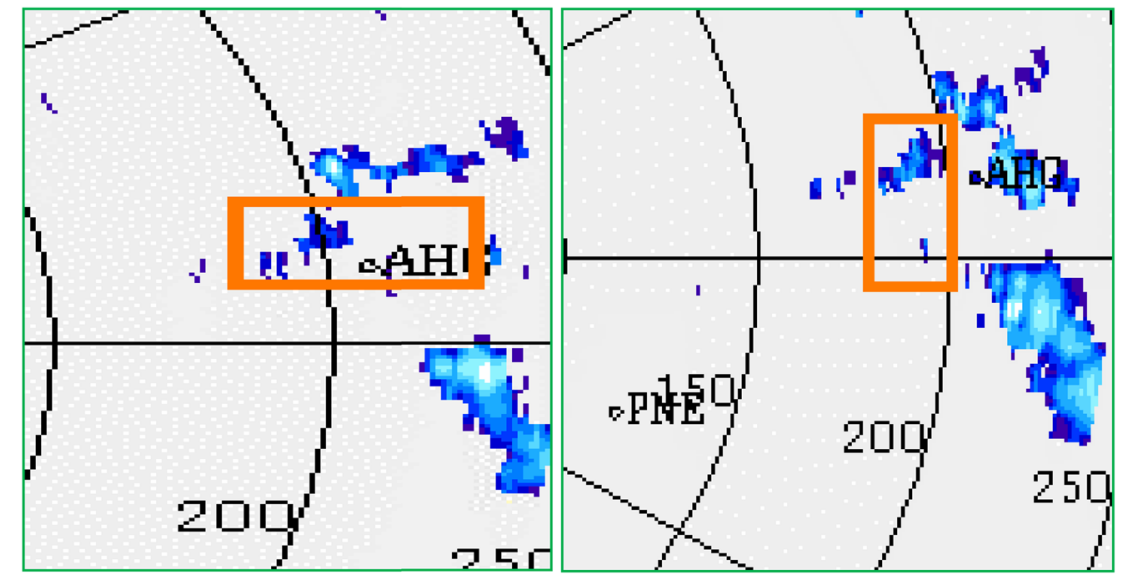

(a)

(b)

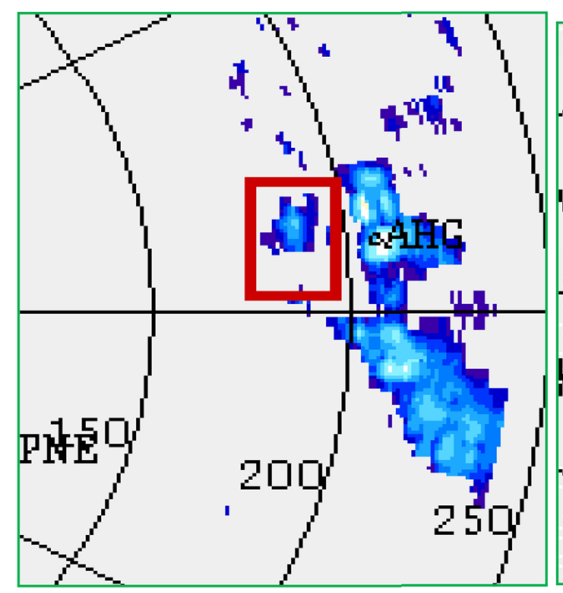

(c)

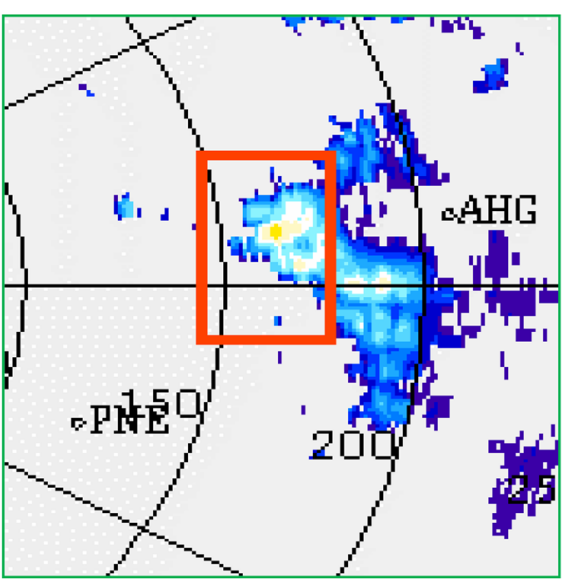

(d)

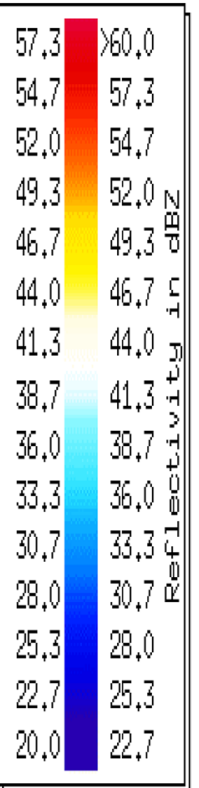

Fig. 11 (02 Jun 2013, Mumbai). a Cluster inside the rectangular shed with reflectivity: $23 \mathrm{dBZ}$ (16:33 Z UTC). b Cluster inside the rectangular shed with reflectivity: 32 dBZ (16:52 Z UTC). c Cluster inside the rectangular shed with reflectivity: $34 \mathrm{dBZ}$ (17:11 Z UTC). d Cluster inside the rectangular shed with reflectivity: $45 \mathrm{dBZ}$ (18:27 Z UTC) correctly predicted hailstorm or no hailstorm, albeit mostly QGH is not valid out of 'QGH-Rectangle' regime.

\subsection{Reaction time}

RT computation is most consistent for data set $D_{12}^{12}$. Relatively lowest standard deviation in error indicates reliable range of reaction time 17.3-29.6 min. Maximum RT of $43 \mathrm{~min}$ is predicted by $D_{10}^{5}$; it is an indication that some (slower) growing cumulus can provide reasonably large reaction time of $43 \mathrm{~min}$ for conducting the seeding operation.

For fast-growing cumulus, it could be as low as 14 min only. Negative error differences are worrisome from operational safety point of view. It ranges from 1 to $13 \mathrm{~min}$. $\ln D_{10}^{5}$, the maximum negative value is $8 \mathrm{~min}$, which is lowest amongst the three data sets. Hence, from operational safety point of view 10-min scan interval is safer for prediction of reaction time by PHDA. If the shorter than 10-min scan time interval, data will give larger and safer prediction by PHDA is scope for further research. 


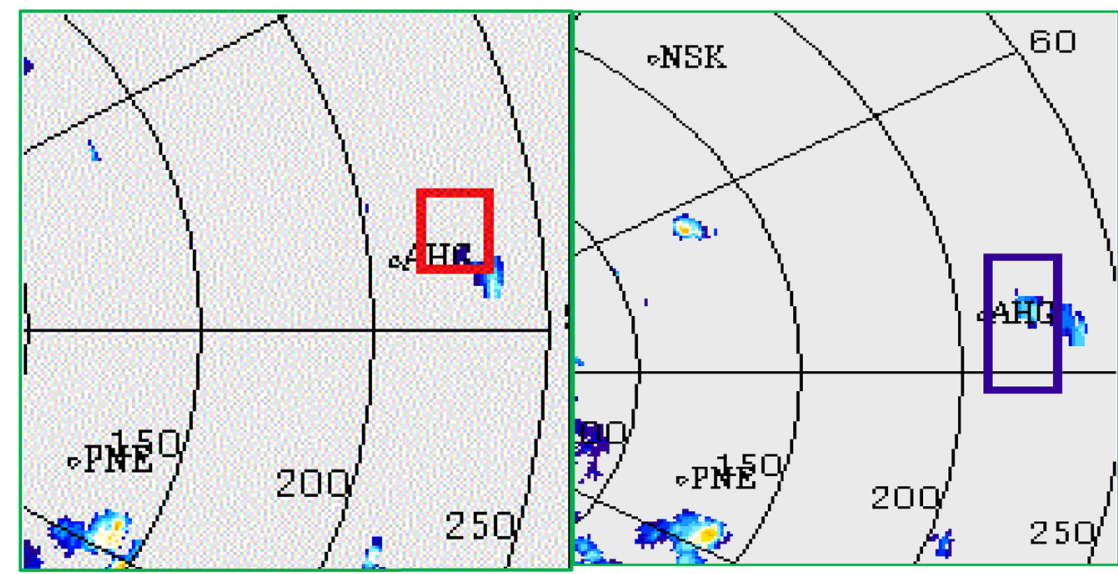

(a)

(b)

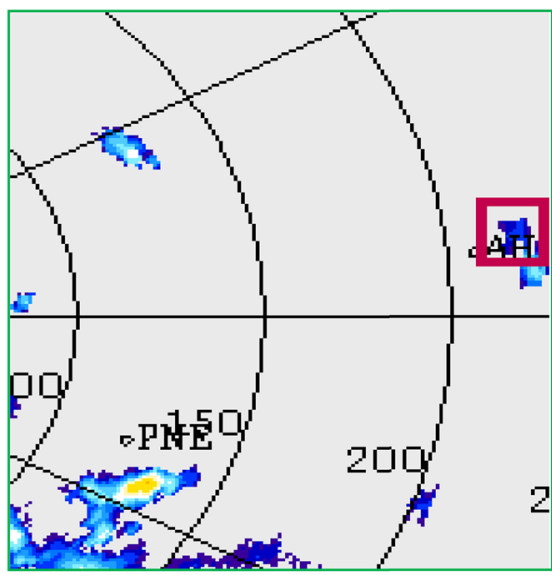

(c)

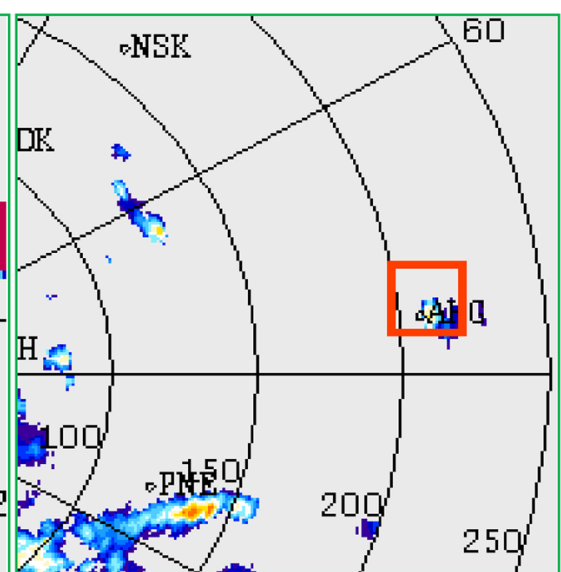

(d)
Fig. 12 (03 Jun 2013, Mumbai). a Cluster inside the rectangular shed with reflectivity: $22 \mathrm{dBZ}$ (09:39 Z UTC). b Cluster inside the rectangular shed with reflectivity: 33 dBZ (09:58 Z UTC). c Cluster inside the rectangular shed with reflectivity: $23 \mathrm{dBZ}$ (10:17 Z UTC). d Cluster inside the rectangular shed with reflectivity: $45 \mathrm{dBZ}$ (10:36 Z UTC)

\subsection{Speed of cumulus}

Cumulus data indicated that cumulus motion speed could range from $5 \mathrm{~m} / \mathrm{s}$ to as high as $19.3 \mathrm{~m} / \mathrm{s}$. This could be due to the regional and seasonal variability in the upper wind conditions in the Indian subcontinent.

A comparative study of errors in speed prediction by linear extrapolation, of 12 clusters each from $D_{10}^{5}, D_{12}^{12}$ and $D_{19}^{8}$, shows higher degree of accuracy (i.e. mean error $\leq 1 \mathrm{~m} / \mathrm{s}$ ) in case of $D_{12}^{12}$ and $D_{19}^{8}$. However, relatively least standard deviation in errors in $D_{19}^{8}$ indicated larger scan interval would exhibit more consistent and reliable speed prediction with the presented extrapolation method.

\section{Conclusion}

(1) Quadratic Growth Hypothesis makes good (100\%) and satisfactory (62.5\%) predictions for slow- and moderate-growing rate of cumulus cloud, respectively. Interestingly, Fig. 13 shows that all growing cumuli falling within the rectangle $0.45 \times 0.6$ appear to empirically follow QGH. Hence, it may be termed as 'QGH-Rectangle'. Although, to firmly authenticate the prediction, in future studies, it may verified for other regions, too, with larger data set.

(2) QGH mostly fails to predict fast-growing cumulus and also for cases when rate of growth temporarily reverses. It warrants research for different algorithms in future studies, to formulate fast and reverse 


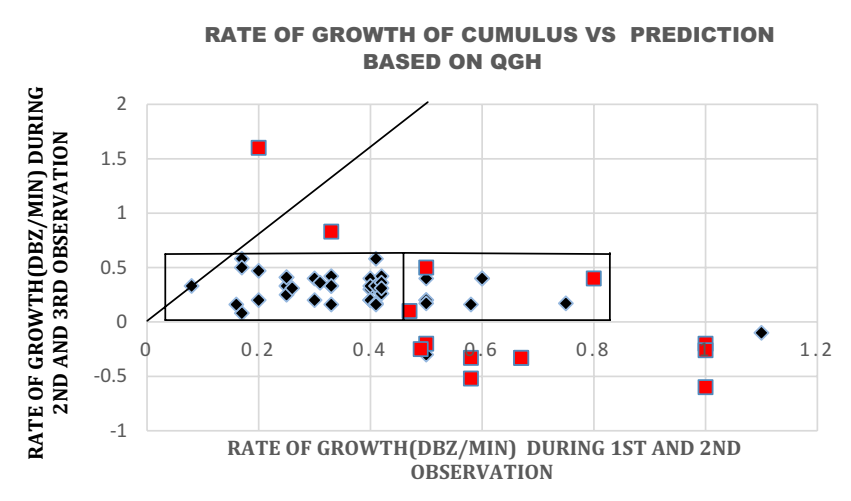

Fig. 13 Blue and red dots correspond to correct and incorrect predictions of hailstorm or no hailstorm based on QGH. Note that average growing cumulus conforming to QGH fall in the primary growth rate of $0.1-0.8 \mathrm{dBZ} / \mathrm{min}$. Cumuli falling within the left rectangle $(0.45 \times 0.6$-termed as ' $\mathrm{QGH}$-Rectangle') perfectly conform to QGH. Hypothesis is $62.5 \%$ accurate in the right rectangle. Interestingly in two cases of reverse growth, too, QGH could correctly predict hailstorm or no hailstorm albeit mostly QGH is not valid out of large rectangle regime

growth, too. Albeit, it is noted that QGH predicted sometimes correctly, under these categories, too, twice in the present study.

(3) As most cumulus growth falls in the category of slow or moderate range, the skill score based on the QGHbased algorithm is 0.79 for $D_{10}^{5}, D_{12}^{12}$. For $D_{19}^{8}$, it is bit lower (0.75).

(4) High 'cumulus reverse growth' of the order of $-5.2 \mathrm{dBZ} / \mathrm{min}$ was observed in the present study.

(5) For hail mitigation campaigns, 10-min scan interval is operationally safe for RT computation. In most of the cases, RT may range from 17.3 to $29.6 \mathrm{~min}$. Maximum RT of 43 min was also noted for slow-growing cumulus. If shorter than 10-min scan time interval, data will give larger RT, which is scope for further research. Hence, efficacy of PHDA for shorter scan interval data ( $<10 \mathrm{~min}$ ) may be further examined in future researches to help compute better 'reaction time'.

6) Cumulus motion speed was observed ranging from $5 \mathrm{~m} / \mathrm{s}$ to as high as $19.3 \mathrm{~m} / \mathrm{s}$. Larger scan interval gives relatively better accuracy in speed computation through PHDA.

Acknowledgements We are deeply grateful to Indian Council of Agricultural Research (National Initiative of Climate Resilient Agriculture) for funding this project entitled 'Hailstorm Management Strategy in Agriculture'. We are also thankful to MIT-World Peace University, Pune, Maharashtra, India, for providing the laboratory space. We are also grateful to Director General, India Meteorological Department, for providing free access to radar data from various IMD Radar centres. Authors are particularly thankful to Mr. K. C. Sai Krishnan (Delhi) and
Mr. S. G. Kamble (Mumbai) of India Met Department for promptly providing radar data. Authors are also thankful to the reviewers of this paper for constructive remarks.

Funding This study was funded by (ICAR/NICRA/Hail/2011) Indian Council of Agricultural Research.

\section{Compliance with ethical standards}

Conflict of interest The authors declare that they have no conflict of interest.

\section{References}

1. Bally J (2004) Generating severe weather warnings from TITAN and SCIT thunderstorm tracks. Weather Forecast 19:64-72

2. Boak TIS III, Jagodnik AJ Jr., Marshall RB, Riceman D, Young MJ (1977) Tracking and significance estimator. R\&D equipment information Rep., contract AFGL-TR-77-0259, Raytheon, Wayland, MA. [Available from Raytheon Company, 141 Spring St., Lexington, MA 02173]

3. Brady PJ, Schroeder MJ, Poellot MR (1978) Automatic identification and tracking of radar echoes in HIPLEX. Preprints, 18th conference on radar meteorology, Atlanta, GA, American Meteorological Society, pp 139-143

4. DeMott JP (1982) A characterization of mixed silver iodide-silver chloride ice nuclei. Atmospheric science paper no. 349, Department of Atmospheric Science, Colorado State University, CO, U.S.A

5. Dennis MG (1975) Testing of cloud seeding materials at the cloud simulation and aerosol laboratory, 1971-1973. J Appl Meteor 14:883-890

6. Dixon M, Wiener G (1993) TITAN: thunderstorm identification, tracking, analysis, and nowcasting - a radar-based methodology. J Atmos Oceanic Technol 10:785-797

7. Federer B, Waldvogel A, Schmid W, Schiesser HH, Hampel F, Schweingruber M, Stahel W, Bader J, Mezeix JF, Doras N, D'Aubigny G, DerMegreditchian G, Vento D (1986) Main results of Grossversuch IV. J Clim Appl Meteor 25:917-957

8. Forsyth DE (1979) Real time forecasting of echo-centroid motion. M.S. thesis, Department of Meteorology, University of Oklahoma [Available from University of Oklahoma, Norman, OK73019]

9. Gonzalez R, Woods R, Eddins S (2012) Digital image processing using MATLAB, 5th edn. Tata McGraw-Hill, New York City. ISBN 978-0-07-070262-2

10. Jackson ME, Jesuroga RT (1995) The ATMS convective area guidance product. Preprints, sixth conference on aviation weather systems, Dallas, TX, American Meteorological Society, pp 78-82

11. Johnson JT, MacKeen PL, Witt A, De Wayne Mitchell E, Stumpf GJ, Eilts MD, Thomas KW (1998) The storm cell identification and tracking algorithm: an enhanced WSR-88D algorithm. Weather Forecast 13:263-276

12. Knight CA, Foote GB, Summers PW (1979) Results of randomized hail suppression experiment in northeast Colorado. Part IX: overall discussion and summary in the context of physical research. J Appl Meteorol 18:1526-1537

13. Kumar $P$ (2017) Hailstorm prediction, control and damage assessment. CRC Press and BS Publication, Boca Raton. ISBN 978-1-1380-4777-8 
14. Kumar P, Pati DP (2015) Radar imageries information extraction and its use in pre-hail estimation algorithm. MAUSAM 66(4):695-712

15. Kumar $P$ (2018) Towards design and development of isothermal cloud chamber for seeding experiments in tropics and testing of pyrotechnic cartridge. J Atmos Solar Terr Phys 181 (Part B):79-93

16. Lakshamanan V, Rabin R, DeBrunner V (2003) Multiscale storm identification and forecast. J Atmos Res 67:367-380

17. Lakshamanan V, Smith T, Stumpf G, Hondl KD (2007) The warning decision support system integrated information. Weather Forecast 22:596-612

18. Lakshamanan V, Fritz A, Smith T, Hondl K, Stumpf G (2007) An automated technique to quality control radar reflectivity data. J Appl Meteorol Climatol 46(3):288-305

19. Lynn R, Lakshmanan V (2002) Virtual radar volumes: creation, algorithm access and visualization. In: Proceedings of 21 conference on severe local storms, American Meteorological Society, San Antonio, TX

20. Rogers RR, Yuan MK (2006) A short course in cloud physics, III edn. Butterworth-Heinemann Pub, Oxford

21. Roy SS, Bhowmik SR, Srivastava K, Mukhopadhyay B, Thampi SB, Reddy YK, Singh H, Venkateswaralu S, Adhikary S (2011) Processing of Indian doppler weather radar data for mesoscale applications. Meteorol Atmos Phys 111:133-147

22. Singh H, Datta RK, Chand S, Mishra D, Kannan B (2011) A study of hail storm of 19th April 2010 over Delhi using Doppler weather radar observations. Mausam 62(3):433-440

23. Srivastava K, Lau S, Yeung HY, Bhardwaj R, Kannan AM, Singh $\mathrm{H}$ et al (2011) Use of SWIRLS now casting systems for quantitative precipitation forecasting using Indian DWR data. Mausam 63(1):1-16
24. Stumpf GJ, Witt A, Mitchell ED, Spencer PL, Johnson JT, Eilts MD, Thomas KW, Burgess DW (1998) The national severe storms laboratory mesocyclone detection algorithm for the WSR-88D. Weather Forecast 13:304-326

25. Stumpf GJ, Smith TM, Gerard AE (2002) The multiple-radar severe storm analysis program (MR-SSAP) for WDSS-II. In: Proceedings of 21 conference on severe local storms, American Meteorological Society, San Antonio, TX, pp 138-141

26. Sulakvelidze GK (1969) Rainstorm and hail. IPST Press, Jerusalam

27. Wilk KE, Gray KC (1970) Processing and analysis techniques used with the NSSL weather radar system. Preprints, 14th radar meteorology conference, Tucson, AZ, American Meteorological Society, pp 369-374

28. Witt A (1990) A hail core aloft detection algorithm. Preprints, 16th conference severe local storms and conference atmosphere. Electricity, Kananaskis Park, American Meteorological Society, Boston, pp 232-235

29. Witt A, Eilts MD, Stumpf GJ, Johnson JT, Michell ED (1998) An enhanced hail detection algorithm for the WSR-88D. Weather Forecast 13(2):286-303

30. Zittel WD (1976) Computer applications and techniques for storm tracking and warning. Preprints, 17 th conference on radar meteorology, Seattle, WA, American Meteorological Society, pp 514-521

Publisher's Note Springer Nature remains neutral with regard to jurisdictional claims in published maps and institutional affiliations. 